\title{
Higher Order Beliefs and the Comovement of Asset Prices*
}

\author{
Christian Grisse ${ }^{\dagger}$ \\ University of Cambridge
}

November 2007

\begin{abstract}
Asset price correlations are often thought to be larger than justified by economic fundamentals. This paper shows that such 'excessive' comovement can be explained by introducing higher order beliefs - investors' beliefs about the beliefs of other investors - into an otherwise standard asset pricing model. Compared to expectations of fundamentals, expectations of other investors' expectations of fundamentals place more weight on public information. In a framework with multiple risky assets whose fundamentals are related, this effect magnifies spillover of public information noise across assets and generates price correlations which are larger than justified by the correlations of underlying fundamentals. The results of this paper are directly applicable in explaining the robust empirical finding of excessive asset price comovement. Our results also imply that financial contagion can be interpreted as overreaction to 'foreign' public information, which occurs because investors try to second-guess the market.
\end{abstract}

JEL classification: D82, D84, G11, G12, G14, G15

Keywords: Higher order beliefs, Excess comovement, Information spillovers, Contagion, Asset pricing

\section{Introduction}

Financial markets exhibit a large degree of comovement, which is often thought to be excessive compared to the underlying fundamental economic variables. ${ }^{1}$ In this paper we ask whether a model in which asset prices are determined by higher order beliefs - investors' beliefs about the beliefs of other investors - can explain this excessive comovement. We study the role of higher order beliefs in a model with multiple risky assets, using numerical methods developed by Townsend (1983). It is well known that higher order beliefs - compared to expectations about economic fundamentals - are biased towards public information. We show that this feature leads to excessive spillover of public information noise across assets with related economic

*I thank Petra Geraats and Chris Meissner for helpful discussions, and Philippe Bacchetta for providing the programs for his paper Bacchetta and van Wincoop (2006). I also thank participants at the Cambridge Macroeconomics Workshop for their comments.

${ }^{\dagger}$ Faculty of Economics, University of Cambridge, Sidgwick Avenue, Cambridge CB3 9DD, UK. E-mail: cg326@cam.ac.uk

${ }^{1}$ See e.g. Barberis, Shleifer and Wurgler (2005) for stock markets, Sutton (2000) for bond markets and Pindyck and Rotemberg (1990) for commodity markets. 
fundamentals and generates price correlations which are larger than justified by fundamentals. Our results are important because they show that a standard asset pricing model with a realistic information structure can explain the robust empirical finding of 'excessive' asset price comovement, without the need to assume investor irrationality or financial frictions.

The idea that higher order beliefs (henceforth HOB) are important in financial markets was first introduced by Keynes (1936), and has recently been incorporated in formal asset pricing models. ${ }^{2}$ When investors care about the resale value of assets they need to form expectations not only about the assets' fundamentals (for example future dividends), but also about future prices. However, these prices are in turn determined by the expectations of investors who are then in the market. Therefore, investors in fact need to form expectations not only about fundamentals directly, but also about the expectations of future investors.

In most asset pricing models the information structure is designed such that expectations of other investors' expectations of future payoffs simplify trivially to expectations about future payoffs. However Allen, Morris and Shin (2006) emphasize that with a more general information structure, the law of iterated expectations fails to hold for average beliefs. Consider a financial market where investors have access to both public information - information that is observed by everyone in the market - and private information, which is only observed by individual investors. Since investors know that other investors have observed the same public information as well, public information is a better predictor of market opinion than their private information. Therefore when forming HOB investors will place excessive weight on public information and consequently prices will reflect public information excessively, where 'excessive' is defined as compared to the statistically optimal forecast of fundamentals.

The contribution of this paper is to show that the presence of $\mathrm{HOB}$ also has implications for asset price comovement. Consider two risky assets whose payoffs are related. Suppose some news is released which indicates that asset one's fundamental value (the present value of discounted future payoffs) will be lower than previously expected. Because payoffs across assets are correlated, rational investors will revise their expectations of asset two's fundamental value downward as well. Moreover, since prices are determined by HOB they will overreact to public information: the fall in the price of asset two in response to the news about the first asset will be larger than justified by the expected fall in asset two's fundamentals. This overreaction of asset prices to information about other assets can be interpreted as financial contagion.

Empirical studies on excess comovement typically regress asset prices on a set of economic fundamentals, and then test for comovement among the residuals; the finding that the covariances of the residuals are non-zero is then interpreted as 'excess comovement'. In terms of our model, the corresponding question is whether there is comovement conditional on economic fundamentals. We show that the presence of public information affecting investors' expectations indeed generates non-zero correlations after conditioning on fundamentals. Moreover, our key finding is that asset price correlations conditional on true fundamentals are larger than justified by the comovement of statistically optimal forecasts of fundamentals, because the presence

\footnotetext{
${ }^{2}$ See e.g. Allen, Morris and Shin (2006) and Bacchetta and van Wincoop (2007).
} 
of HOB magnifies the comovement arising from public information. Thus even though all investors are fully rational, the model generates an inefficient amount of comovement across asset prices. We therefore conclude that $\mathrm{HOB}$ can contribute to explaining the seemingly excessive comovement that is observed in financial markets and confirmed by various empirical studies.

We examine these issues formally in a multi-period asset pricing model based on Admati (1985), which is presented in section 2. In our model, investors trade two risky assets with correlated payoffs. HOB arise in financial markets because investors care about future prices. We use an overlapping-generations framework to include this feature in the simplest possible way. Since our full model has no analytical solution, in section 3 and 4 we instead derive analytical results for a simplified version of our model. Section 5 solves the full model by adapting numerical methods developed by Townsend (1983) to the multiple-asset case. The key results, that $\mathrm{HOB}$ generate information spillovers across prices and price correlations across assets in excess of what is justified by the comovement of underlying fundamentals, carry over from the simplified version to the general model.

The paper builds on the growing literature in higher-order expectations. ${ }^{3}$ However, to the best of our knowledge, there is so far only one study that analyzes HOB with multiple risky assets: Zhou (1998) focuses on portfolio diversification and does not analyze the effect of HOB on asset price comovement. Moreover, the type of HOB analyzed is fundamentally different from this paper: while this paper features HOB in a dynamic context - today's expectations of tomorrow's expectations -, in Zhou (1998) HOB exist in a static framework. ${ }^{4}$ Our paper is most closely related to Bacchetta and van Wincoop (2006) and Allen, Morris and Shin (2006). Bacchetta and van Wincoop (2006) show that HOB magnify the impact and persistence of liquidity shocks ("rational confusion") and thereby help to explain the short-term disconnect of exchange rates from fundamentals. We use their information structure to generate HOB in a model with multiple risky assets. Allen, Morris and Shin (2006) show in a finite horizon model that with $\mathrm{HOB}$, prices will differ systematically from fundamentals. We extend their results to the multi-asset case in the simplified version of our model.

The relationship of this paper to theoretical and empirical studies on excess comovement and financial contagion is discussed in section 6. The finding that HOB magnify correlation conditional on economic fundamentals is directly applicable to findings in the empirical literature. Depending on the parameter values our model generates significantly more comovement than standard present value models, in line with empirical findings. Our analysis adds to and incorporates previous theories of how shocks are transmitted across the financial system. We show that several transmission channels highlighted in the literature on financial contagion are magnified when $\mathrm{HOB}$ are taken into account, while others become less important. We also dis-

\footnotetext{
${ }^{3}$ For applications of HOB to fields other than financial markets see Lorenzoni (2006) for business cycles and Woodford (2003) and Nimark (2007) for monetary policy.

${ }^{4}$ In Zhou (1998), there are two groups of investors; when extracting price signals, each group needs to form expectations about the other group's expectations. But the other group's expectations are in turn determined by expectations of the first group, and so on. Starting with Townsend (1983), most of the literature considers such static HOB. For applications to financial markets see also Singleton (1987), Hussman (1992) and Pagratis (2005).
} 
cuss policy implications of our analysis. We find that correlations are closer to what is justified by the comovement of fundamentals when public information is more accurate. This suggests that transparency on behalf of policymakers may help to limit excessive comovement.

\section{The model}

\subsection{Model setup}

The model is a dynamic version of Admati (1985), describing a financial market with multiple risky assets whose payoffs are correlated. As is standard in the literature, we assume that investors have constant absolute risk aversion (CARA) utility, asset payoffs are normally distributed and there is random asset supply which prevents prices from fully revealing investors' private information.

Assets. There are three assets in the economy: two risky assets, and one riskless asset with a gross return of $R \geq 1$. The riskless asset is in perfectly elastic supply, and its price is normalized to one. The risky assets generate cashflows $\theta_{1 t}$ and $\theta_{2 t}$ in period $t$, which we call fundamentals: for example, the risky assets can be interpreted as stocks, and their fundamentals as dividends. Fundamentals of asset $j$ are persistent and follow autoregressive processes,

$$
\theta_{j t}=\rho_{j} \theta_{j t-1}+\varepsilon_{j t}
$$

with $-1<\rho_{j}<1$, where $\varepsilon_{j t}$ is a disturbance which is correlated across assets:

$$
\left[\begin{array}{l}
\varepsilon_{1 t} \\
\varepsilon_{2 t}
\end{array}\right] \sim \text { i.i.d.N }\left(\left[\begin{array}{l}
0 \\
0
\end{array}\right],\left[\begin{array}{cc}
\sigma_{\theta 1}^{2} & \rho \\
\rho & \sigma_{\theta 2}^{2}
\end{array}\right]\right)
$$

Throughout the paper we assume $\rho>0$, so that fundamentals are positively related across assets. The supply of asset $j$ is described by

$$
S_{j t}=\phi_{j} S_{j t-1}+s_{j t}
$$

with $-1<\phi_{j}<1$, where

$$
\left[\begin{array}{l}
s_{1 t} \\
s_{2 t}
\end{array}\right] \sim \text { i.i.d.N }\left(\left[\begin{array}{l}
0 \\
0
\end{array}\right],\left[\begin{array}{cc}
\sigma_{s 1}^{2} & \rho_{s} \\
\rho_{s} & \sigma_{s 2}^{2}
\end{array}\right]\right)
$$

Asset supplies $S_{1 t}$ and $S_{2 t}$ could be interpreted as liquidity shocks. More generally these supplies are the result of trading for reasons other than profit maximization. Some investors may for example trade to manage their liquidity positions, or may be forced to sell assets in response to margin calls or deposit liquidations.

Investors. The model has an overlapping-generations structure: in each period, a continuum of investors indexed on the unit interval is born. Investors live for two periods: in the first period 
when 'young' they purchase their asset portfolio from the 'old' generation, given exogenous initial wealth; and when 'old' in the second period they sell all asset holdings to the new young generation, consume and die. We follow the standard assumption that investors have constant absolute risk aversion (CARA) utility and are born with exogenous initial wealth which is large enough so that they are never wealth constrained.

The overlapping-generations framework is a convenient way to model investors who care about future prices. Nevertheless, the model is clearly an oversimplification as in this framework there is no role for long-term investors who could possibly bet against shorter-term trends. However, even investors with a long-term horizon will care about shorter-term asset price developments, so that our results do not depend on the assumption of overlapping generations. ${ }^{5}$ In reality, many investors trade primarily to speculate on future price developments. Furthermore, most investors are leveraged, borrowing funds at lower interest rates to invest them in assets with higher risk and higher return. To borrow funds they need to provide collateral, such as the assets in their portfolio. When asset prices fall, the value of their portfolio declines so that they need to provide additional collateral, which is costly. Therefore leveraged investors will care about short-term asset price changes, even if they trade mainly to exploit longer-term trends. Also, fund managers are often evaluated regularly according to the market value of their portfolios and therefore have an incentive to maximize shorter-term portfolio values.

Information. We model the information structure analogous to Bacchetta and van Wincoop (2006). In period $t$, current fundamentals $\theta_{1 t}$ and $\theta_{2 t}$ are revealed, which can be used to compute prior distributions for future fundamentals $\theta_{1 t+1}, \theta_{2 t+1}, \ldots$ Investors also have access to two further sources of information. First, a typical investor $i$ in period $t$ receives private signals $x_{1 i t s}$ and $x_{2 i t s}$ about fundamentals in period $s$,

$$
x_{j i t s}=\theta_{j s}+\eta_{j i t s}
$$

for $j=1,2$ and $s=t+1, t+2, \ldots, t+T$. The error terms are normally distributed according to

$$
\left[\begin{array}{c}
\eta_{1 i t s} \\
\eta_{2 i t s}
\end{array}\right] \sim \text { i.i.d.N }\left(\left[\begin{array}{l}
0 \\
0
\end{array}\right],\left[\begin{array}{cc}
\sigma_{x 1}^{2} & 0 \\
0 & \sigma_{x 2}^{2}
\end{array}\right]\right)
$$

Investors' private information can be interpreted either as their personal opinions or forecasts, or as saying that they literally do have private (inside) information, for example about specific companies. Second, in every period $t$ new public signals about fundamentals $T$ periods ahead are revealed:

$$
z_{j t+T}=\theta_{j t+T}+\zeta_{j t+T}
$$

\footnotetext{
${ }^{5}$ See the appendices of Bacchetta and van Wincoop (2003) and Allen, Morris and Shin (2006) for examples of models with higher order beliefs and long-term investors. The qualitative results of Allen, Morris and Shin (2006) are unchanged when allowing for long-term investors, and the numerical results in Bacchetta and van Wincoop (2003) for the overlapping-generations and infinite-horizon investor case are nearly identical.
} 
for $j=1,2$ where

$$
\left[\begin{array}{l}
\zeta_{1 t+T} \\
\zeta_{2 t+T}
\end{array}\right] \sim \text { i.i.d.N }\left(\left[\begin{array}{l}
0 \\
0
\end{array}\right],\left[\begin{array}{cc}
\sigma_{z 1}^{2} & 0 \\
0 & \sigma_{z 2}^{2}
\end{array}\right]\right)
$$

Investors observe the history of public signals up to $t$. Finally, investors also observe current and past prices. Since prices will aggregate the expectations of individual investors they can be used to extract additional information about fundamentals. The information set $I_{i t}$ of a typical investor $i$ in period $t$ then includes current fundamentals, public signals, current and past prices and $i$ 's private information:

$$
I_{i t}=\left\{\theta_{1 t}, \theta_{2 t} ; \mathbf{x}_{1 i t+T}, \mathbf{x}_{2 i t+T}, \mathbf{z}_{1 t+T}, \mathbf{z}_{2 t+T} ; \mathbf{p}_{1 t}, \mathbf{p}_{2 t}\right\}
$$

where $\mathbf{p}_{j t}$ contains prices for asset $j$ from periods $t-T+1$ to $t$, and $\mathbf{x}_{j i t}$ and $\mathbf{z}_{j t}$ contain private and public signals for fundamentals from periods $t+1$ to $t+T$. Note that public signals $z_{j t}$ from period $t$ and earlier are irrelevant for investors in period $t$ since current fundamentals are observed in $t$. Furthermore, in period $t-T$ investors have only received information about fundamentals up to $t$, so that prices in from periods $t-T$ and earlier also do not provide any useful information from the perspective investors in period $t$.

We follow the standard assumption of the rational expectations literature that the structure of the economy and in particular the accuracy of information is common knowledge.

Timing. Within each period $t$ the timing is as follows. In the beginning of the period, fundamentals are realized and holders of risky assets receive the cashflows $\theta_{j t}$. A new young generation of investors is born and public signals $z_{j t+T}$ and private signals $x_{j i t s}, s=t+1, \ldots, t+T$, are revealed. Then trade takes place at prices $p_{j t}$ : the new young generation submits their demand for risky assets and the old generation liquidates their asset holdings. Finally the old generation of investors consumes their wealth and dies.

\subsection{Portfolio choice and the relevance of higher order beliefs}

In this subsection we analyze investors' portfolio choice and show why higher order beliefs arise in our model. Consider the optimization problem of a typical investor $i$ in period $t$. Denote $i$ 's demands for risky assets by the column vector $\mathbf{D}_{i t}$ whose $j$ th entry denotes the demand for risky asset $j$. The investor has initial wealth $w_{i t}$, and CARA utility. Therefore he maximizes

$$
E_{i t}\left(w_{i t+1}\right)-\frac{\gamma}{2} \operatorname{Var}_{i t}\left(w_{i t+1}\right)
$$

where $\gamma$ is the coefficient of absolute risk aversion and $w_{i t+1}$ is final wealth in period $t+1$. The subscript it indicates that expectation and variance are conditional on the information set $I_{i t}$. The payoff of holding risky assets in any period $t$ is the sum of next period's dividend and the asset price. Therefore final wealth is given by

$$
w_{i t+1}=\mathbf{D}_{i t}^{\prime}\left(\boldsymbol{\theta}_{t+1}+\mathbf{p}_{t+1}\right)+R\left(w_{i t}-\mathbf{D}_{i t}^{\prime} \mathbf{p}_{t}\right)
$$


where $\boldsymbol{\theta}_{t}=\left[\begin{array}{ll}\theta_{1 t} & \theta_{2 t}\end{array}\right]^{\prime}$ and $\mathbf{p}_{t}=\left[\begin{array}{ll}p_{1 t} & p_{2 t}\end{array}\right]^{\prime}$. The conditional variance of final wealth is

$$
\operatorname{Var}_{i t}\left(w_{i t+1}\right)=\mathbf{D}_{i t}^{\prime} \operatorname{Var}_{i t}\left(\boldsymbol{\theta}_{t+1}+\mathbf{p}_{t+1}\right) \mathbf{D}_{i t}
$$

Since the precision of private signals is identical across investors we can write

$$
\operatorname{Var}_{i t}\left(\boldsymbol{\theta}_{t+1}+\mathbf{p}_{t+1}\right)=\operatorname{Var}_{t}\left(\boldsymbol{\theta}_{t+1}+\mathbf{p}_{t+1}\right) \equiv \boldsymbol{\Sigma}_{\theta p, t}
$$

From the first order condition we then have

$$
\mathbf{D}_{i t}=\frac{1}{\gamma} \boldsymbol{\Sigma}_{\theta p, t}^{-1}\left[E_{i t}\left(\boldsymbol{\theta}_{t+1}+\mathbf{p}_{t+1}\right)-R \mathbf{p}_{t}\right]
$$

Equilibrium requires that for every period, aggregate demand for each asset equals its random supply:

$$
\int_{0}^{1} \mathbf{D}_{i t} d i=\mathbf{S}_{t}
$$

where $\mathbf{S}_{t}=\left[\begin{array}{cc}S_{1 t} & S_{2 t}\end{array}\right]^{\prime}$. Combining this equilibrium condition with equation (1) above and rearranging yields ${ }^{6}$

$$
\mathbf{p}_{t}=\frac{1}{R}\left[\bar{E}_{t}\left(\boldsymbol{\theta}_{t+1}+\mathbf{p}_{t+1}\right)-\gamma \boldsymbol{\Sigma}_{\theta p, t} \mathbf{S}_{t}\right]
$$

where average expectations have been defined as

$$
\bar{E}_{t}(\theta)=\int_{0}^{1} E_{i t}(\theta) d i
$$

As usual, prices are equal to the assets' expected discounted future payoffs, corrected for the associated uncertainty. Iterating (2) forward gives

$$
\mathbf{p}_{t}=\frac{1}{R}\left\{\sum_{k=0}^{\infty} \frac{1}{R^{k}} \bar{E}_{t}^{k+1}\left(\boldsymbol{\theta}_{t+1+k}\right)-\gamma \boldsymbol{\Sigma}_{\theta p, t+k} \bar{E}_{t}^{k}\left(\mathbf{S}_{t+k}\right)\right\}
$$

where higher-order expectations have been written as

$$
\bar{E}_{t}^{k}(\theta) \equiv \bar{E}_{t} \bar{E}_{t+1} \ldots \bar{E}_{t+k-1}(\theta)
$$

with $\bar{E}_{t}^{0}(\theta) \equiv \theta$ and $\bar{E}_{t}^{1}(\theta) \equiv \bar{E}_{t}(\theta)$. Thus prices today are determined by the average expectation of next period's dividends, plus the average expectations of next period's average expectation of dividends two periods ahead, and so on, adjusted for risk.

\footnotetext{
${ }^{6}$ Although our CARA-Gaussian framework has been widely used in the theoretical literature, it does have well-known limitations. However, equation (2), which is the starting point of our analysis, can also be derived with an alternative model setup where investors are assumed to have constant relative risk aversion (CRRA) utility, while asset payoffs are log-normally distributed. The results are identical, although the derivation requires some first- and second-order approximations. Details can be obtained from the author upon request.
} 
As emphasized by Morris and Shin (2002) and Allen, Morris and Shin (2006, henceforth AMS), the law of iterated expectations does not generally hold for average expectations. HOB differ from standard expectations because public information is a better predictor of tomorrow's average expectations than private information. Intuitively, this is the case if both private and public information received today are still informative in the future. Then future investors will continue to use today's public information to forecast fundamentals, together with their own private information. Therefore today's investors forming expectations about future average expectations will use both the public signals and their private information to predict future average private signals. Furthermore, they use today's public signal to predict next period's use of today's public signal, thus placing additional weight on public information. ${ }^{7}$

In our framework the choice of information horizon $T$ determines whether HOB will differ from standard expectations of economic fundamentals. If $T>1$, information sets of young and old investors overlap and both public and private information received in period $t$ are still informative in $t+1$. Thus we have ${ }^{8}$

$$
\bar{E}_{t}\left(\theta_{t+k}\right) \neq \bar{E}_{t} \bar{E}_{t+1} \ldots \bar{E}_{t+k-1}\left(\theta_{t+k}\right) \quad \text { if } \quad T>1
$$

\section{Model solution for a special case}

Unfortunately, the general model presented in the last section has no analytical solution. To illustrate the effect of higher-order beliefs on asset price comovement this section therefore discusses a special case of the model which does allow the derivation of analytical results. We later show numerically that these results carry over to the general case. For now we simplify the model as follows:

1. The horizon is finite. The last trading period is denoted by $\bar{T}$.

2. Risky payoffs for assets 1 and 2 in the final period $\bar{T}+1$ are denoted by $\theta_{1}$ and $\theta_{2}$. There are no payoffs in intermediate periods.

3. Payoffs $\theta_{1}$ and $\theta_{2}$ are drawn in an initial period from the prior distribution

$$
\left[\begin{array}{l}
\theta_{1} \\
\theta_{2}
\end{array}\right] \sim N\left(\left[\begin{array}{l}
y_{1} \\
y_{2}
\end{array}\right],\left[\begin{array}{cc}
\sigma_{\theta 1}^{2} & \rho \\
\rho & \sigma_{\theta 2}^{2}
\end{array}\right]\right)
$$

with $\rho>0$, but are not revealed until the final period $\bar{T}$. In the initial period, the public signals $z_{1}$ and $z_{2}$ are realized and revealed,

$$
\left[\begin{array}{l}
z_{1} \\
z_{2}
\end{array}\right] \sim N\left(\left[\begin{array}{l}
\theta_{1} \\
\theta_{2}
\end{array}\right],\left[\begin{array}{cc}
\sigma_{z 1}^{2} & 0 \\
0 & \sigma_{z 2}^{2}
\end{array}\right]\right)
$$

\footnotetext{
${ }^{7}$ See Allen, Morris and Shin (2006) for a neat illustration, and Bacchetta and van Wincoop (2007) for a formal proof of the conditions under which HOB differ from standard expectations in a related setting.

${ }^{8}$ Note that when $T>1$, investors in $t$ receive information which is still useful for investors in $t+1$. Therefore we do not require fundamentals to be persistent $\left(\rho_{j} \neq 0\right)$ for HOB to differ from average expectations of fundamentals.
} 
4. In each period $t \leq \bar{T}$, a typical investor $i$ receives private signals $x_{1 i t}$ and $x_{2 i t}$ about payoffs in the final period:

$$
\left[\begin{array}{l}
x_{1 i t} \\
x_{2 i t}
\end{array}\right] \sim \text { i.i.d.N }\left(\left[\begin{array}{l}
\theta_{1} \\
\theta_{2}
\end{array}\right],\left[\begin{array}{cc}
\sigma_{x 1}^{2} & 0 \\
0 & \sigma_{x 2}^{2}
\end{array}\right]\right)
$$

5. Asset supplies are not persistent, $\phi_{1}=\phi_{2}=0$, so that $S_{j t}=s_{j t} .{ }^{9}$ Furthermore the covariance of supply shocks is zero, $\rho_{s}=0$.

6. Investors do not observe current or past prices.

7. For simplicity, we also assume that the risk-free rate is one: $R=1$.

With these simplifications our model becomes an extension of the model in Allen, Morris and Shin (2006), now including two risky assets. In contrast to their model we here also assume that investors do not observe prices so that we can derive analytical results about asset price correlations. However this assumption does not change the qualitative results as is shown by numerical simulations in section five. ${ }^{10}$

Since fundamentals are now only realized in the final period and asset supplies are not persistent, today's expectations of tomorrow's prices simplify to HOB about fundamentals in the final period. Therefore with the above assumptions equation (3) boils down to

$$
\begin{aligned}
\mathbf{p}_{t} & =\bar{E}_{t} \bar{E}_{t+1} \ldots \bar{E}_{\bar{T}}(\boldsymbol{\theta})-\gamma \operatorname{Var}_{t}\left(\mathbf{p}_{t+1}\right) \mathbf{s}_{t} \quad \text { for } t<\bar{T} \\
\mathbf{p}_{\bar{T}} & =\bar{E}_{\bar{T}}(\boldsymbol{\theta})-\gamma \operatorname{Var}_{\bar{T}}(\boldsymbol{\theta}) \mathbf{s}_{\bar{T}}
\end{aligned}
$$

where $\mathbf{s}_{t}=\left[\begin{array}{ll}s_{1 t} & s_{2 t}\end{array}\right]^{\prime}$.

The information set of a typical investor $i$ in period $t$ is given by $I_{i t}=\left\{y_{1}, y_{2}, z_{1}, z_{2}, x_{1 i t}, x_{2 i t}\right\}$. Since all variables in $I_{i t}$ and fundamentals $\theta_{1}$ and $\theta_{2}$ are jointly normally distributed, the projection theorem can be used to compute investor $i$ 's expectations:

$$
\begin{aligned}
& E\left(\theta_{1} \mid I_{i t}\right)=a_{11} y_{1}+a_{12} y_{2}+c_{11} z_{1}+c_{12} z_{2}+b_{11} x_{1 i t}+b_{12} x_{2 i t} \\
& E\left(\theta_{2} \mid I_{i t}\right)=a_{21} y_{1}+a_{22} y_{2}+c_{21} z_{1}+c_{22} z_{2}+b_{21} x_{1 i t}+b_{22} x_{2 i t}
\end{aligned}
$$

where the coefficients are defined in appendix A. Note that $a_{12}$ and $a_{21}$ are negative, while all other coefficients are positive. Intuitively, whenever the public signal $z_{1}$ or the private signal $x_{1 i t}$ corresponding to the first asset is larger than the prior $y_{1}$, investors will assume that the difference is partly due to the fundamentals $\theta_{1}$ being larger than the prior. Since fundamentals

\footnotetext{
${ }^{9}$ This assumption considerably simplifies the analysis. It would be more intuitive in the context of the overlapping-generations framework of the model (where in each period the investors from the old generation liquidate their asset holdings) if liquidity shocks had a positive mean, which would not change any of the results below. See AMS (2006) for a discussion.

${ }^{10}$ When investors do observe prices the presence of higher order beliefs implies that the impact of supply noise on prices is magnified. This additional role of supply noise is discussed in section five. Our results here can also be understood as the case where the variance of supply noise becomes very large. As the supply noise volatility approaches infinity, prices provide no information and will not be used (in the limit) when forming expectations.
} 
are positively correlated investors will then also revise their forecast of fundamentals of the second asset, $\theta_{2}$ upwards. All else equal, a larger prior $y_{1}$ therefore decreases expectations about the second asset's fundamentals, and vice versa.

For expectations of asset $i$ 's fundamentals, the weights placed on information directly about asset $i$ sum to one,

$$
a_{i i}+b_{i i}+c_{i i}=1
$$

whereas the weights placed on information directly about asset $j, j \neq i$, sum to zero:

$$
a_{i j}+b_{i j}+c_{i j}=0
$$

We assume that when taking average expectations the law of large numbers holds so that errors in private signals average out:

$$
\bar{E}_{t}\left(x_{1 i t}\right)=\int_{0}^{1} x_{1 i t} d i=\theta_{1}
$$

This assumption is frequently used in the literature. ${ }^{11}$ In our case, this will not change the results qualitatively, although it may affect their quantitative importance as discussed in the next section. With this assumption, the private signals $x_{1 i t}$ and $x_{2 i t}$ in (5) and (6) are replaced by the true fundamentals, $\theta_{1}$ and $\theta_{2}$, when forming average expectations. This gives

$$
\begin{aligned}
& \bar{E}_{t}\left(\theta_{1}\right)=a_{11} y_{1}+a_{12} y_{2}+c_{11} z_{1}+c_{12} z_{2}+b_{11} \theta_{1}+b_{12} \theta_{2} \\
& \bar{E}_{t}\left(\theta_{2}\right)=a_{21} y_{1}+a_{22} y_{2}+c_{21} z_{1}+c_{22} z_{2}+b_{21} \theta_{1}+b_{22} \theta_{2}
\end{aligned}
$$

Higher order expectations can then be derived by iterating on (9) and (10). For example, average expectations about $\theta_{1}$ in period $t+1$ are given by

$$
\bar{E}_{t+1}\left(\theta_{1}\right)=a_{11} y_{1}+a_{12} y_{2}+c_{11} z_{1}+c_{12} z_{2}+b_{11} \theta_{1}+b_{12} \theta_{2}
$$

In period $t$ a typical investor $i$ will then form expectations about next period's average expectations $\bar{E}_{t+1}\left(\theta_{1}\right)$ according to

$$
E_{i t} \bar{E}_{t+1}\left(\theta_{1}\right)=a_{11} y_{1}+a_{12} y_{2}+c_{11} z_{1}+c_{12} z_{2}+b_{11} E_{i t}\left(\theta_{1}\right)+b_{12} E_{i t}\left(\theta_{2}\right)
$$

Using (9) and (10) and averaging across investors we get

$$
\begin{aligned}
\bar{E}_{t} \bar{E}_{t+1}\left(\theta_{1}\right)= & \left(a_{11}+b_{11} a_{11}+b_{12} a_{21}\right) y_{1}+\left(a_{12}+b_{11} a_{12}+b_{12} a_{22}\right) y_{2} \\
& +\left(c_{11}+b_{11} c_{11}+b_{12} c_{21}\right) z_{1}+\left(c_{12}+b_{11} c_{12}+b_{12} c_{22}\right) z_{2} \\
& +\left(b_{11}^{2}+b_{12} b_{21}\right) \theta_{1}+\left(b_{11} b_{12}+b_{12} b_{22}\right) \theta_{2}
\end{aligned}
$$

\footnotetext{
${ }^{11}$ See Admati (1981) for a discussion.
} 
Following AMS (2006) the computation of higher order expectations can be simplified as follows. First, define vectors $\mathbf{Z}$ and $\mathbf{Z}_{i t}$, where

$$
\begin{aligned}
\mathbf{Z} & =\left[\begin{array}{llllll}
y_{1} & y_{2} & z_{1} & z_{2} & \theta_{1} & \theta_{2}
\end{array}\right]^{\prime} \\
\mathbf{Z}_{i t} & =\left[\begin{array}{llllll}
y_{1} & y_{2} & z_{1} & z_{2} & x_{1 i t} & x_{2 i t}
\end{array}\right]^{\prime}
\end{aligned}
$$

Furthermore define a matrix $\mathbf{B}$ such that

$$
E_{i t}(\mathbf{Z})=\mathbf{B} \cdot \mathbf{Z}_{i t}
$$

This matrix is given by

$$
\mathbf{B}=\left[\begin{array}{cccccc}
1 & 0 & 0 & 0 & 0 & 0 \\
0 & 1 & 0 & 0 & 0 & 0 \\
0 & 0 & 1 & 0 & 0 & 0 \\
0 & 0 & 0 & 1 & 0 & 0 \\
a_{11} & a_{12} & c_{11} & c_{12} & b_{11} & b_{12} \\
a_{21} & a_{22} & c_{21} & c_{22} & b_{21} & b_{22}
\end{array}\right]
$$

Note that unlike in AMS (2006) our matrix B is constant over time, since the information set of investors does not grow over time as more and more past prices are observed. Using $\mathbf{B}$ we can describe how higher-order expectations evolve through time. In period $\bar{T}$ expectations of investors $i$ are given by

$$
E_{i \bar{T}}(\mathbf{Z})=\mathbf{B} \cdot \mathbf{Z}_{i \bar{T}}
$$

Averaging over all investors we get

$$
\bar{E}_{\bar{T}}(\mathbf{Z})=\mathbf{B} \cdot \mathbf{Z}
$$

Now consider period $\bar{T}-1$, when investors need to form expectations about average opinion in the final period $\bar{T}$. For a typical investor $i$, we have

$$
\begin{aligned}
E_{i \bar{T}-1} \bar{E}_{\bar{T}}(\mathbf{Z}) & =E_{i \bar{T}-1}(\mathbf{B} \cdot \mathbf{Z}) \\
& =\mathbf{B} \cdot E_{i \bar{T}-1}(\mathbf{Z}) \\
& =\mathbf{B}^{2} \cdot \mathbf{Z}_{i \bar{T}-1}
\end{aligned}
$$

So average expectations in $\bar{T}-1$ of average expectations in $\bar{T}$ equal

$$
\bar{E}_{\bar{T}-1} \bar{E}_{\bar{T}}(\mathbf{Z})=\mathbf{B}^{2} \cdot \mathbf{Z}
$$

In general higher order expectations in period $t$ are given by

$$
\begin{aligned}
\bar{E}_{t} \bar{E}_{t+1} \ldots \bar{E}_{\bar{T}}(\mathbf{Z}) & =\mathbf{B}^{\bar{T}-t+1} \cdot \mathbf{Z} \\
& \equiv \mathbf{B}_{t}^{*} \cdot \mathbf{Z}
\end{aligned}
$$


We can write matrix $\mathbf{B}_{t}^{*}$ as

$$
\mathbf{B}_{t}^{*}=\left[\begin{array}{cccccc}
1 & 0 & 0 & 0 & 0 & 0 \\
0 & 1 & 0 & 0 & 0 & 0 \\
0 & 0 & 1 & 0 & 0 & 0 \\
0 & 0 & 0 & 1 & 0 & 0 \\
a_{1 t}^{1 *} & a_{2 t}^{1 *} & c_{1 t}^{1 *} & c_{2 t}^{1 *} & b_{1 t}^{1 *} & b_{2 t}^{1 *} \\
a_{1 t}^{2 *} & a_{2 t}^{2 *} & c_{1 t}^{2 *} & c_{2 t}^{2 *} & b_{1 t}^{2 *} & b_{2 t}^{2 *}
\end{array}\right]
$$

so that higher order expectations are given by

$$
\begin{aligned}
& \bar{E}_{t} \bar{E}_{t+1} \ldots \bar{E}_{\bar{T}}\left(\theta_{1}\right)=a_{1 t}^{1 *} y_{1}+a_{2 t}^{1 *} y_{2}+c_{1 t}^{1 *} z_{1}+c_{2 t}^{1 *} z_{2}+b_{1 t}^{1 *} \theta_{1}+b_{2 t}^{1 *} \theta_{2} \\
& \bar{E}_{t} \bar{E}_{t+1} \ldots \bar{E}_{\bar{T}}\left(\theta_{2}\right)=a_{1 t}^{2 *} y_{1}+a_{2 t}^{2 *} y_{2}+c_{1 t}^{2 *} z_{1}+c_{2 t}^{2 *} z_{2}+b_{1 t}^{2 *} \theta_{1}+b_{2 t}^{2 *} \theta_{2}
\end{aligned}
$$

From the definition of $\mathbf{B}_{t}^{*}$, we have $\mathbf{B}_{t-1}^{*}=\mathbf{B}_{t}^{*} \cdot \mathbf{B}$. Writing out this product we can derive differential equations that describe how the weights placed on the various pieces of information evolve over time. For $j=1,2$ we have

$$
\begin{aligned}
& a_{1 t-1}^{j *}=a_{1 t}^{j *}+b_{1 t}^{j *} a_{11}+b_{2 t}^{j *} a_{21} \\
& a_{2 t-1}^{j *}=a_{2 t}^{j *}+b_{1 t}^{j *} a_{12}+b_{2 t}^{j *} a_{22} \\
& c_{1 t-1}^{j *}=c_{1 t}^{j *}+b_{1 t}^{j *} c_{11}+b_{2 t}^{j *} c_{21} \\
& c_{2 t-1}^{j *}=c_{2 t}^{j *}+b_{1 t}^{j *} c_{12}+b_{2 t}^{j *} c_{22} \\
& b_{1 t-1}^{j *}=b_{1 t}^{j *} b_{11}+b_{2 t}^{j *} b_{21} \\
& b_{2 t-1}^{j *}=b_{1 t}^{j *} b_{12}+b_{2 t}^{j *} b_{22}
\end{aligned}
$$

with initial conditions $a_{j \bar{T}}^{i *}=a_{i j}, c_{j \bar{T}}^{i *}=c_{i j}$ and $b_{j \bar{T}}^{i *}=b_{i j}$. It is straightforward to show that the coefficients in $\mathbf{B}_{t}^{*}$ sum similarly to the coefficients in $\mathbf{B}$, namely that we have ${ }^{12}$

$$
\begin{aligned}
& a_{i t}^{i *}+b_{i t}^{i *}+c_{i t}^{i *}=1 \\
& a_{j t}^{i *}+b_{j t}^{i *}+c_{j t}^{i *}=0 .
\end{aligned}
$$

for $i, j=1,2$ and $i \neq j$.

\footnotetext{
${ }^{12}$ The proof is by induction: first, note that (19) and (20) hold for the final period $\bar{T}$ since

$$
\begin{aligned}
a_{i \bar{T}}^{i *}+b_{i \bar{T}}^{i *}+c_{i \bar{T}}^{i *} & =a_{i i}+b_{i i}+c_{i i}=1 \\
a_{j \bar{T}}^{i *}+b_{j \bar{T}}^{i *}+c_{j \bar{T}}^{i *} & =a_{i j}+b_{i j}+c_{i j}=0
\end{aligned}
$$

for $i \neq j$. Next, show that if (19) and (20) hold for $t$, then they will also hold for $t-1$. This follows after substituting for $a_{j t}^{i *}+b_{j t}^{i *}+c_{j t}^{i *}$ using equations (13) to (18).
} 
Substituting our results into the pricing equation (4) leads to the following expression for asset prices:

$$
\begin{aligned}
p_{1 t}= & a_{1 t}^{1 *} y_{1}+a_{2 t}^{1 *} y_{2}+c_{1 t}^{1 *} z_{1}+c_{2 t}^{1 *} z_{2}+b_{1 t}^{1 *} \theta_{1}+b_{2 t}^{1 *} \theta_{2} \\
& -\gamma \operatorname{Var}_{t}\left(p_{1 t+1}\right) s_{1 t}-\gamma \operatorname{Cov}_{t}\left(p_{1 t+1}, p_{2 t+1}\right) s_{2 t} \\
p_{2 t}=\quad & a_{1 t}^{2 *} y_{1}+a_{2 t}^{2 *} y_{2}+c_{1 t}^{2 *} z_{1}+c_{2 t}^{2 *} z_{2}+b_{1 t}^{2 *} \theta_{1}+b_{2 t}^{2 *} \theta_{2} \\
& -\gamma \operatorname{Var}_{t}\left(p_{2 t+1}\right) s_{2 t}-\gamma \operatorname{Cov}_{t}\left(p_{1 t+1}, p_{2 t+1}\right) s_{1 t}
\end{aligned}
$$

In the following, we focus on properties of higher order expectations. In particular, we will analyze the degree to which asset prices, through $\mathrm{HOB}$, reflect public information and fundamentals, and the comovement of asset prices induced by HOB. We therefore do not need to solve explicitly for the variance and covariance of prices.

\section{Results}

This section derives analytical results about asset price comovement for the special case of the model. We summarize our results in three propositions. First, we extend a result emphasized in Morris and Shin (2002) and AMS (2006) to a setting with multiple risky assets: higher order beliefs about fundamentals place excessive weight on public (as opposed to private) information, where 'excessive' is defined relative to the statistically optimal forecast of fundamentals.

Proposition 1 (Excessive reaction to public information)

In the asset pricing equations (and $H O B$ ), the weights placed on public signals, $z_{1}$ and $z_{2}$, about fundamentals are increasing in the expectation horizon and larger than the corresponding weights in the statistically optimal forecast of fundamentals, except for the final period: in (21) and (22) we have

$$
c_{j t}^{i *}>c_{j t+1}^{i *}>\ldots>c_{j \bar{T}-1}^{i *}>c_{j \bar{T}}^{i *}=c_{i j}
$$

for $i, j=1,2$.

Proof. This result follows directly from (15) and (16).

This result implies that public information about the fundamentals of one asset have an excessive impact on the price of another asset whose fundamentals are related: the movement in asset prices - corresponding to the change in HOB - is larger than justified by the change in the market's average expectation of fundamentals.

Proposition 1 shows how HOB can contribute to explaining financial contagion - the seemingly excessive spillover of financial crises across markets and countries. Consider two countries, 1 and 2, whose economic fundamentals are positively correlated (for example, both countries are emerging markets which have similar economic circumstances). Following the release of negative public information (for example a credit rating downgrade) for country $1, z_{1}<0$, asset prices $p_{1 t}$ fall. Furthermore because prices are determined by higher order expectations they will overreact to the public news. A credit rating downgrade for country 1 will also make investors 
worry that country 2 , with similar economic fundamentals, might face a downgrade in the near future as well: there is a higher, but only slightly higher probability of a crisis in country 2 . However, because investors' beliefs about other investors' expectations are important, investors place an excessive weight on the public signal 'credit rating downgrade for country 1'. Investors revise their expectations about fundamentals in country 2 by more than seems justified by the negative information released about country 1 . Therefore, asset prices in country 2 will drop more substantially, and contagion occurs:

$$
\frac{\partial p_{2 t}}{\partial z_{1}}=\frac{\partial \bar{E}_{t} \bar{E}_{t+1} \ldots \bar{E}_{T}\left(\theta_{2}\right)}{\partial z_{1}}=c_{1 t}^{2 *}>\frac{\partial \bar{E}_{t}\left(\theta_{2}\right)}{\partial z_{1}}=c_{21}
$$

A shock to one market generates price movements in other markets which are excessive relative to average expectations of the underlying fundamentals. In a model with multiple risky assets, higher order expectations therefore have the potential to explain why financial crises can have large effects on markets whose fundamentals are only mildly related.

The next result extends proposition 1 in AMS (2006) to the case of multiple risky assets.

Proposition 2 (Price drift)

Prices deviate systematically from fundamentals: in (21) and (22) we have

$$
b_{j t}^{j *}<b_{j t+1}^{j *}<\ldots<b_{j \bar{T}-1}^{j *}<b_{j \bar{T}}^{j *}=b_{j j}
$$

for $j=1,2$.

Proof. See appendix B.

Over time, asset prices increasingly reflect fundamentals: there is price drift. This result is again driven by the feature that with HOB investors place excessive weight on public information. As the number of iterations in HOB decreases, the reliance on public information declines as well. In the final period the payoff from holding risky assets is just equal to their fundamentals $\theta_{j}$, so that asset prices are determined by average expectations about fundamentals.

We now turn to analyzing asset price comovement. We are interested in the difference in comovement between the HOB model and the standard present value (PV) model where prices equal expected discounted future cashflows, $p_{j t}=\bar{E}_{t}\left(\theta_{j}\right)$. Compared to the PV model, HOB affect asset price comovement in two ways: first, they affect the comovement of investors' expectations, and second they affect the comovement of risk premia. We focus here on the first effect; in the numerical simulation in section 5 we consider the second effect as well. One way to think about correlations that ignore comovement from risk premia is that they capture the case when the amount of noise from liquidity trades is very small. Except for times of market turmoil this is likely to be the case in reality. With HOB, covariances of prices are higher compared to the classical model (see appendix B for a proof), but price volatility is higher as well. To judge whether market comovement increases it is therefore more useful to look at the correlation rather than the covariance. 
For our analytical result we focus on comovement conditional on true fundamentals. This is a useful indicator of market inefficiency induced by HOB, since we would expect asset price comovement to be determined by comovement of fundamentals. Furthermore, correlations conditional on true fundamentals are the relevant measure for comparison with empirical work. In empirical studies excess comovement is typically defined as the presence of non-zero covariances among the residuals from a regression of asset prices on economic fundamentals. For example, Shiller (1990), Beltratti and Shiller (1993) and Engsted and Tanggard (2004) regress stock prices on real dividends, using yearly data; and Pindyck and Rotemberg $(1990,1993)$, with monthly data, regress commodity price changes and stock returns on a set of macroeconomic variables including output, inflation and exchange rates. In terms of our stylized model these lower-frequency variables correspond to fundamentals $\theta_{j t}$, while public signals $y$ and $z$ correspond to a multitude of public announcements and other information which make up investors' information sets, but which cannot be possibly accounted for in empirical work. In the next result we therefore analyze comovement conditional on true asset payoffs $\theta$ which corresponds most closely to the residual comovement analyzed in empirical work.

\section{Proposition 3 (Excessive correlation)}

Let $\operatorname{corr}\left(\bar{E}_{t} \ldots \bar{E}_{\bar{T}}\left(\theta_{1}\right), \bar{E}_{t} \ldots \bar{E}_{\bar{T}}\left(\theta_{2}\right) \mid \theta_{1}, \theta_{2}\right)$ denote the correlation of higher order expectations about fundamentals $\theta_{1}$ and $\theta_{2}$, conditional on $\theta_{1}$ and $\theta_{2}$; and let $\operatorname{corr}\left(\bar{E}_{t}\left(\theta_{1}\right), \bar{E}_{t}\left(\theta_{2}\right) \mid \theta_{1}, \theta_{2}\right)$ denote the correlation of average expectations about fundamentals $\theta_{1}$ and $\theta_{2}$, conditional on $\theta_{1}$ and $\theta_{2}$. Then we have

$$
\operatorname{corr}\left(\bar{E}_{t} \ldots \bar{E}_{\bar{T}}\left(\theta_{1}\right), \bar{E}_{t} \ldots \bar{E}_{\bar{T}}\left(\theta_{2}\right) \mid \theta_{1}, \theta_{2}\right)>\operatorname{corr}\left(\bar{E}_{t}\left(\theta_{1}\right), \bar{E}_{t}\left(\theta_{2}\right) \mid \theta_{1}, \theta_{2}\right)
$$

\section{Proof. See appendix B.}

The correlation of HOB - conditional on fundamentals $\theta_{1}$ and $\theta_{2}$ - is higher than the correlation of average forecasts of fundamentals. This suggests that (conditional on fundamentals) the correlation of asset prices, which are equal to HOB of fundamentals minus a risk premium, is larger than the correlation of average forecasts of fundamentals as well. In the numerical results below we show that the comovement of risk premia further contributes to excessive comovement. Note that the comovement of average expectations about fundamentals, $\bar{E}_{t}\left(\theta_{j}\right)$ is non-zero because the same public information affects expectations for both assets. The important point however is that this comovement is magnified through HOB. Thus a model with HOB generates significantly more 'excess' comovement than standard asset pricing models.

The assumption that private signals $x_{j i t}$ are unbiased with respect to fundamentals $\theta_{j}$ and uncorrelated across investors should be noted: when there is a large number of investors (indeed, we have assumed an infinite number of investors), errors in private signals average out. This assumption (which is standard in the literature) precludes herding behavior and other psychological biases which may be problematic if markets are hit by waves of optimism and pessimism. A more realistic model would include only a finite number of investors, so that errors in private signals would not wash out. In this case the covariance would include an addi- 
Table 1: Benchmark parameterization

\begin{tabular}{ccccc}
\hline \hline Parameter & Value & & Parameter & Value \\
\cline { 1 - 2 }$\sigma_{\theta j}$ & 0.5 & & $\operatorname{corr}\left(\varepsilon_{1 t}, \varepsilon_{2 t}\right)$ & 0.5 \\
$\sigma_{x j}$ & 0.5 & & $\rho_{s}$ & 0 \\
$\sigma_{z j}$ & 0.5 & & $R$ & 1.01 \\
$\sigma_{s j}$ & 0.5 & & $\gamma$ & 0.5 \\
$\rho_{j}$ & 0.5 & & 5 \\
$\phi_{j}$ & 0 & & \\
\hline \multicolumn{2}{l}{ Parameters are identical across assets $j=1,2}$.
\end{tabular}

tional term containing private signal noise. Our qualitative result would still go through in this richer framework, although it might be quantitatively less important. We stick to the standard assumption concerning private signals to keep the framework tractable and to highlight the main intuition of how $\mathrm{HOB}$ can influence comovement of asset prices.

\section{Simulation of the general model}

This section explores the properties of our general model, which is solved using numerical methods developed by Townsend (1983) and so far only applied by Singleton (1987) and Bacchetta and van Wincoop (2006). ${ }^{13}$ We first present results from a benchmark specification given in Table 1. This parameterization is illustrative only and not calibrated to match actual data. Below we show that the results are robust to changes in the key parameters.

Figure 1 presents impulse response functions for the benchmark parameterization. In particular, it compares the effects of one-standard deviation realizations of different shocks on the price of asset $1, p_{1 t+k}$, for $k=0,1,2, \ldots$, for two models: the HOB model developed in section 2 and the the present value (PV) model where prices equal average expectations of discounted future cashflows, $\bar{E}_{t+k}\left(\sum_{i=1}^{\infty} R^{-i} \theta_{1 t+k+i}\right)$. Note that since fundamentals $\theta_{1 t+T}$ are revealed in period $t+T$, shocks to information about fundamentals in $t+T$ and earlier will not affect prices from $t+T$ onwards.

Panel (a) in Figure 1 shows impulse responses for asset 1 to shocks to the fundamentals of the same asset in $t+T, \theta_{1 t+T}$. Shocks that affect fundamentals in period $t+T$ will affect prices and expectations in $t$ already since investors in $t$ receive unbiased signals about fundamentals up to $T$ periods ahead. A positive shock to fundamentals $\theta_{1 t+T}$ raises prices in the HOB-model by more than in the PV-model. This is in line with proposition 2 in the previous section: prices deviate systematically from fundamentals because they are determined by HOB, which reflect public information excessively. The impulse response functions for prices in both models slope upwards initially: as more information is revealed over time, investors learn about the true value of fundamentals and hence both expectations of discounted future cashflows and HOB become more responsive to fundamentals. Because fundamentals are persistent shocks to period $t+T$ 's

\footnotetext{
${ }^{13}$ For details see appendix C. It should be noted that the model has multiple equilibria because the conditional (co-)variances of asset prices are endogenous. In our numerical analysis we focus on the stable, low-variance equilibrium. See Bacchetta and van Wincoop (2003) for details.
} 
(a) Shocks to fundamentals $\theta_{1 t+T}$

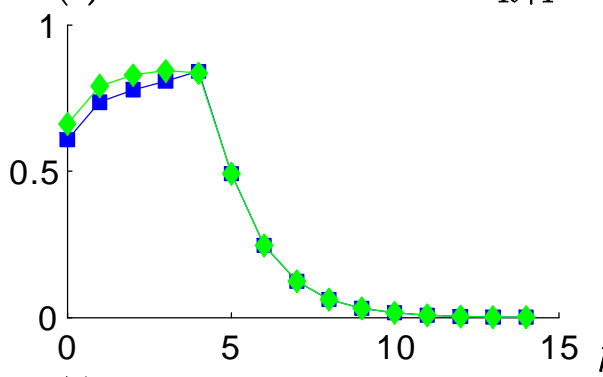

(c) Shocks to public signals $z_{1 t+T}$

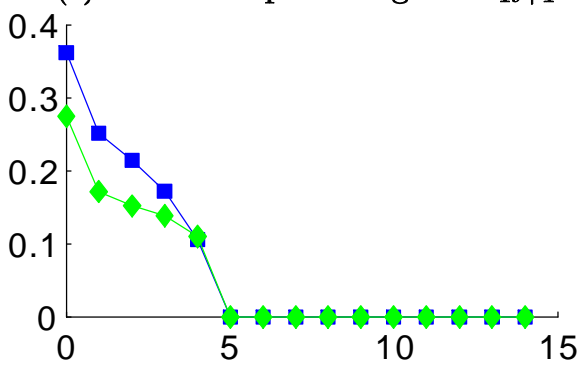

(e) Supply shocks $s_{1 t}$

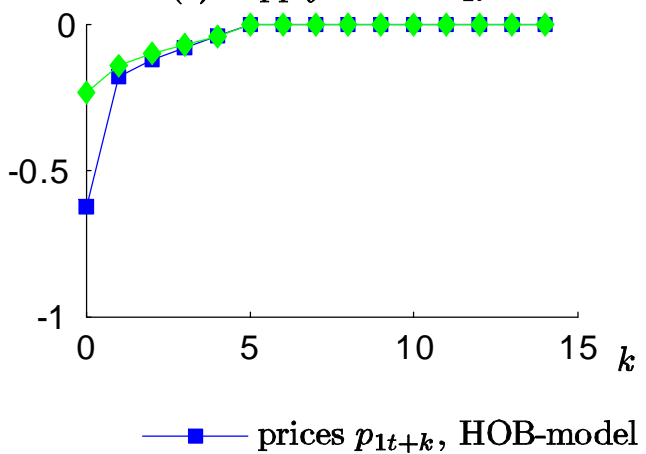

(b) Shocks to fundamentals $\theta_{2 t+T}$

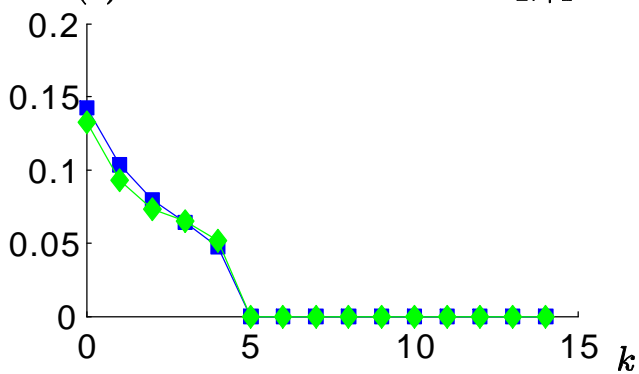

(d) Shocks to public signals $z_{2 t+T}$

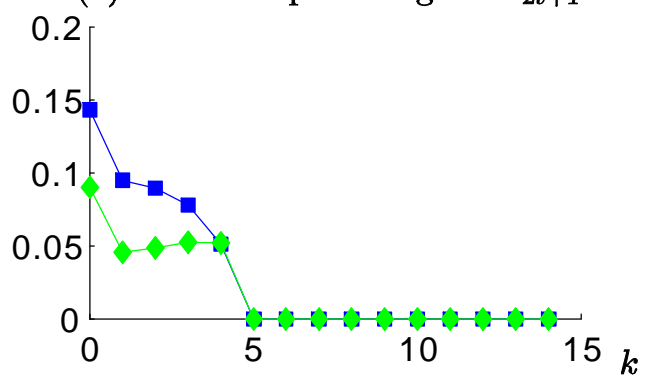

(f) Supply shocks $s_{2 t}$

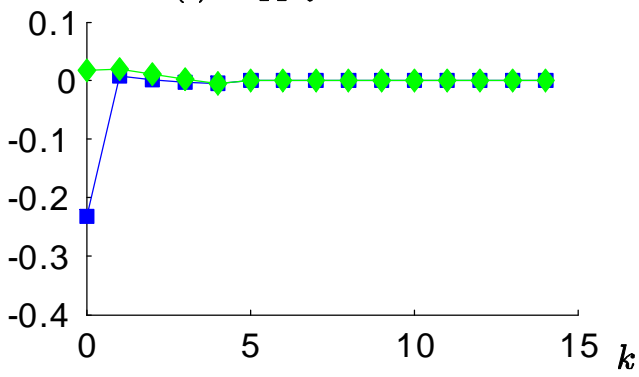

Figure 1: Correlations conditional on true fundamentals. Parameters as stated in Table 1, except for parameter on $\mathrm{x}$-axis.

fundamentals continue to affect prices and expectations even after the fundamentals have been revealed in $t+T$. However, after $t+T$ the weight placed on shocks to $\theta_{1 t+T}$ declines since $\rho_{1}<1$.

Panels (b) to (f) show impulse responses to shocks to asset 2's fundamentals, public signals noise, and liquidity shocks. These shocks essentially represent errors that the investors make when using private signals, public signals and prices to form expectations about asset 1 's fundamentals. Over time, investors learn the true value of fundamentals and make smaller forecast mistakes so that the influence of errors on prices and expectations declines and impulse response functions slope downward. Note that the effect of the various shocks on prices in the HOB-model is larger than the corresponding effect on prices in the PV-model. This is the case because HOB magnify the weight placed on public information such as prices and public signals $z_{j t}$, and thus also magnify the impact of forecast errors that occur through shocks affecting prices (liquidity shocks) and public signals. 
Table 2: Comovement and volatility

\begin{tabular}{lccc}
\hline \hline & Correlation* & Covariance* & Volatility* \\
\hline prices, HOB-model & 0.62 & 0.52 & 0.83 \\
HOB & 0.48 & 0.22 & 0.47 \\
prices, PV-model & 0.34 & 0.09 & 0.27 \\
\hline *
\end{tabular}

${ }^{*}$ Conditional on true fundamentals. Parameters as stated in Table 1.

In panel (b), since fundamentals are positively correlated across assets positive information about asset 2's fundamentals will also raise expectations of fundamentals of the first asset. In panel (d) the effect of noise from asset 2's public signals on asset 1's price in the HOB-model is larger than the effect of the same shock on average expectations about asset 1's discounted future cashflows: there are excessive information spillovers, in line with proposition 1 in the previous section. This follows again because HOB place excessive weight on public information. Panels (e) and (f) show impulse responses to liquidity shocks affecting the supply of the first and second asset, respectively. Supply shocks from the current period, $s_{j t}$ affect the price of the first asset, $p_{1 t}$ through the risk premium channel: since asset returns are risky, risk-averse investors require a greater premium to hold more assets, which decreases the price. Furthermore, both current and past liquidity shocks affect prices and expectations because investors learn about fundamentals from current and past prices which aggregate investors' private information. Since prices are affected by unobserved liquidity shocks, investors mistakenly attribute changes in prices which are due to liquidity shocks partially to changes in fundamentals ('rational confusion').

Table 2 presents summary statistics for comovement and volatility, computed using the benchmark parameterization. We are again interested in explaining comovement conditional on true fundamentals, which in this case corresponds to conditioning on all fundamental shocks, past and future: if there is comovement after controlling for fundamentals then our model can contribute to explaining the excess comovement found in empirical studies, which typically analyze comovement of residuals from a regression of asset prices (or returns) on fundamentals. We compare the comovement of prices $\mathbf{p}_{t}$ in the HOB-model with the comovement prices in PV-model. Furthermore to determine to what degree price correlation can be explained by comovement of risk premia we also compute the correlation of the expectations component of prices, which corresponds to HOB about discounted future cashflows, $\sum_{i=1}^{\infty} R^{-i} \bar{E}_{t}^{i}\left(\boldsymbol{\theta}_{t+i}\right)$.

First, note that the covariance of expected discounted future cashflows across assets is nonzero. This result obtains because of the comovement induced by the presence of public information: information which affects investors' information sets, but cannot be conditioned on in empirical studies (because the data is not available) causes the residuals to co-move if the underlying fundamentals are related. Furthermore, both covariances and variances of asset prices in the HOB-model, conditional on true fundamentals, are higher than the corresponding (co-)variances in the PV-model. Therefore, to analyze how HOB affect comovement it is more useful to look at correlation rather than covariance. Indeed, the correlation of prices with $\mathrm{HOB}$ is larger than in the PV-model. The difference is explained only partly by risk premia comovement, since the correlation of HOB across assets is also larger than the correlation across 
(a)

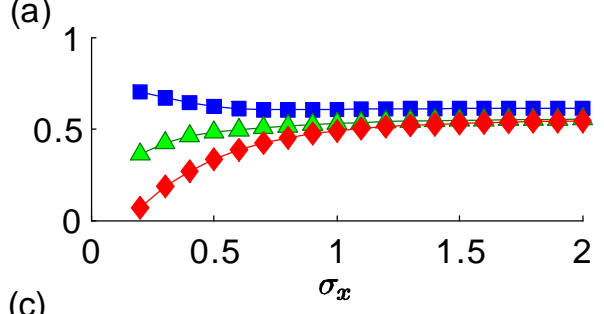

(c)

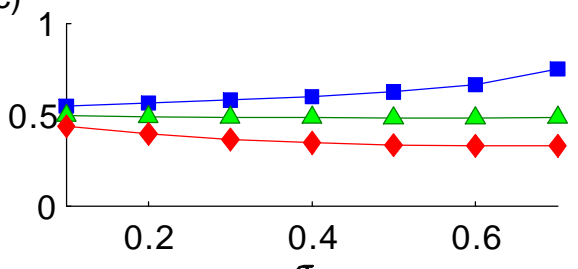

(e)

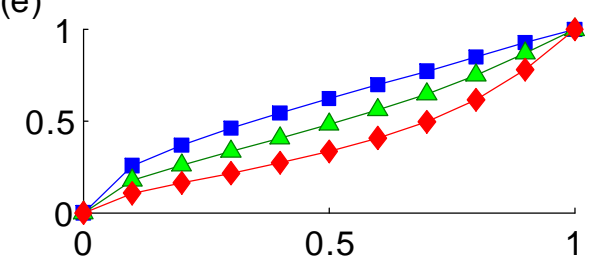

(g)

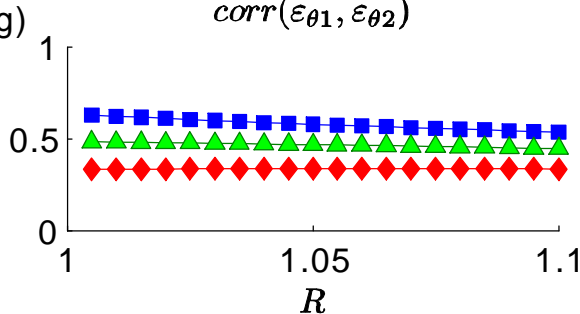

(b)

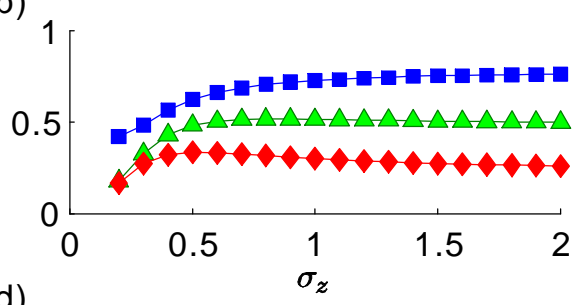

(d)

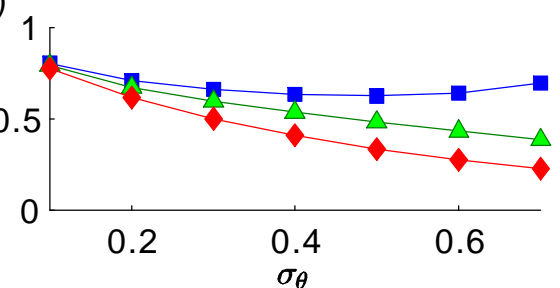

(f)

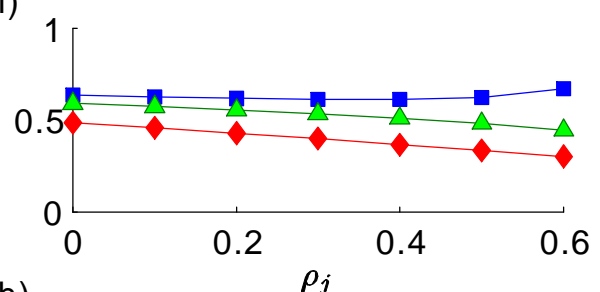

(h)

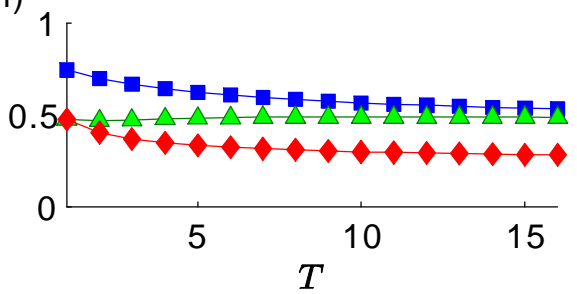

$\longrightarrow$ prices, HOB-model $\longleftarrow$ HOB $\smile$ prices, PV-model

Figure 2: Correlations conditional on true fundamentals. Parameters as stated in Table 1, except for parameter on $\mathrm{x}$-axis.

expected discounted future cashflows. This is consistent with proposition 3 in the previous section. Therefore, accounting for HOB can help to explain the large degree of comovement found in empirical studies.

Figure 2 presents sensitivity analyses for comovement, plotting correlations conditional on fundamentals as in Table 2 and varying one key parameter at a time, while holding the other parameters constant at the benchmark parameterization. The finding that price correlations for the HOB-model are larger than the corresponding correlations when prices equal expected discounted future cashflows (conditional on fundamentals) appears to be robust. Moreover, depending on the deep parameters the difference in price correlation between the HOB- and PVmodels can be large. While a PV-model with a realistic information structure does generate nonzero comovement after controlling for fundamentals, taking HOB into account can significantly increase the amount of comovement. We interpret the difference in correlation between the HOB- and PV-models as 'excess' comovement - correlation which is larger than justified by the 
comovement of underlying fundamentals.

From panels (a) and (b) of Figure 2, note that excess comovement decreases (increases) as private signals (public signals) become less accurate. When private information is more accurate, investors place relatively more weight on private signals; moreover, this effect is stronger for standard expectations of fundamentals than for HOB (which place excessive weight on public information). Consequently, as private signals become more accurate the difference in weight placed on public information in the HOB- and PV-models increases, generating more excess comovement. An increase in the variance of public signals has two effects. First, the weight placed on public information decreases; and secondly, comovement and volatility arising from errors in public signals will be larger. As seen in panel (b) of Figure 2, the overall effect is to increase the amount of excess correlation. The same applies to the liquidity shock variance in panel (c), which determines the accuracy of signals obtained from prices.

Panel (e) shows that excess correlation is highest for intermediate levels of fundamental correlation. Clearly, when fundamentals are completely unrelated, asset prices will be uncorrelated in both models. At the same time, when the correlation of fundamentals approaches one the two assets are identical and all correlations are equal to one. With higher risk-free rates future asset payoffs are more heavily discounted. Consequently the difference between expectations and $\mathrm{HOB}$ of future fundamentals becomes less important for asset prices, and in panel (g), correlations decrease and become less excessive as interest rates increase. Panel (h) of Figure 2 shows that as the information horizon $T$ increases, excess correlation increases as well. As $T$ increases, there is more common information in the information sets of investors in $t$ and $t+1$. As a result, the difference between HOB and standard expectations will be larger, with increased reliance on public information, which magnifies asset price comovement. Furthermore, as $T$ increases investors become more certain about future price developments as the reliance on public information increases. Therefore, the risk premium (the difference between prices and HOB) decreases.

\section{Discussion}

\subsection{Relationship to empirical work}

There is a large empirical literature on excess comovement of asset prices. For example, Shiller (1989), Pindyck and Rotemberg (1993) and Kallberg and Pasquariello (2007) find evidence of excessive correlation across stock markets; Sutton (2000) argues that there is excessive comovement across bond markets; and Pindyck and Rotemberg (1990) find excessive comovement among commodity prices. ${ }^{14}$

According to economic theory, asset prices should reflect economic fundamentals. For example, stock prices should be affected by information about future dividends, such as earnings statements, growth, interest rates and so on. In the empirical literature, comovement is com-

\footnotetext{
${ }^{14}$ The majority of empirical studies finds evidence for excess comovement. For diverging findings see Beltratti and Shiller (1993) for stock markets and Deb et.al. (1996) for commodity markets.
} 
monly considered to be 'excessive' if it cannot be fully explained by economic fundamentals. The strategy typically employed in empirical work is to first regress asset prices on a set of relevant macroeconomic variables, and then to analyze whether there is comovement among the residuals from the regression. If the measures of fundamentals included in the regression fully explain price behavior, the covariance of regression residuals should be equal to zero. Thus the finding that covariances between the residuals are significantly different from zero is taken as evidence that the covariation of fundamentals cannot fully account for all covariation in asset prices.

Fundamentals do not affect asset prices directly, but rather indirectly through their impact on investors' expectations. Furthermore, it is virtually impossible to account for all information that might possibly affect investors' expectations: therefore, it is very likely that the comovement of error terms at least partly reflects comovement of macroeconomic variables that were not included in the regression, but affected investors' expectations. To circumvent this problem Pindyck and Rotemberg $(1990,1993)$ estimate a latent variable model to describe expectations, and then regress asset prices on fundamentals and latent variables. Even after accounting for expectations in this way, however, they find that the covariances of residuals are significantly different from zero and conclude that there is excess comovement.

When the standard present value model is extended to include a more general information structure, prices co-move conditional on fundamentals, in line with empirical studies. This is the case because each asset price is affected by public information about both assets, so that the public signal errors generate comovement. However, the key contribution of this paper is that this comovement is magnified when HOB are taken into account. Sensitivity analyses show that depending on the underlying parameter values, the effect of HOB can be quite large. Therefore, while the PV-model generates comovement, taking HOB into account can contribute to explain the surprisingly high degree of comovement found in empirical studies.

Evaluating the empirical relevance of HOB in financial markets is complicated by the fact that investors' expectations and information sets are not directly observable. A promising alternative to empirical work may therefore be the use of experiments. Currently, the only empirical application of an HOB asset pricing model that we are aware of is Monnin (2005), who analyzes whether a model with $\mathrm{HOB}$ can explain the observed volatility of the pricedividend ratio in U.S. stock markets. He estimates the parameters in his theoretical model from US stock market data and uses past prices and dividends as proxies for the available public information. ${ }^{15}$ He compares the volatility of the dividend-price ratio calibrated from the theoretical model to the volatility of the corresponding actual data and concludes that a model with HOB is consistent with the observed financial market volatility. However one shortcoming of this approach is that only past values are included as measures of public information.

\footnotetext{
${ }^{15}$ As in our model, he assumes that private signal errors wash out across large numbers of investors so that prices depend on true fundamentals directly, rather than on private information.
} 


\subsection{Relationship to previous theoretical work on financial contagion}

Excessive asset price comovement is often labeled financial contagion, although there is no universally accepted definition of what constitutes financial contagion. While most of the empirical literature defines contagion as a significant increase of comovement in times of turmoil ${ }^{16}$, theoretical explanations of contagion seldom distinguish between periods of turmoil and tranquility and instead seem to describe mechanisms which are always at work. ${ }^{17}$ Although the magnification channels described in this paper are at work at all times, it is possible to argue that our model is consistent with an increase in comovement in times of market crises. The excessive impact of public information on prices is proportional to the size of the news shock. To the extent that public signal shocks become larger and more volatile in times of crisis, the spillover effects will become more 'excessive' and asset prices more volatile.

The relationship between our model and some of the existing theories of comovement and contagion can be usefully demonstrated by defining the difference between HOB and standard expectations - called the "higher order wedge" by Bacchetta and van Wincoop (2007) - as follows:

$$
\Delta_{t} \equiv \sum_{k=0}^{\infty} \frac{1}{R^{k}}\left\{\left[\bar{E}_{t}^{k+1}\left(\boldsymbol{\theta}_{t+1+k}\right)-\gamma \boldsymbol{\Sigma}_{\theta p, t+1+k} \bar{E}_{t}^{k+1}\left(\mathbf{S}_{t+1+k}\right)\right]-\bar{E}_{t}\left(\boldsymbol{\theta}_{t+1+k}\right)\right\}
$$

Furthermore let $\boldsymbol{\Sigma}_{\theta, t} \equiv \operatorname{cov}_{t}\left(\sum_{k=1}^{\infty} R^{-k} \boldsymbol{\theta}_{t+k}\right)$ denote the covariance matrix of discounted future fundamentals, conditional on information available to investors in period $t$, and define the following term describing differences in conditional covariance matrices:

$$
\boldsymbol{\Sigma}_{\Delta, t} \equiv \boldsymbol{\Sigma}_{\theta p, t}-\boldsymbol{\Sigma}_{\theta, t}
$$

Then asset pricing equation (3) can be rewritten as follows:

$$
\mathbf{p}_{t}=\frac{1}{R}\left\{\sum_{k=0}^{\infty} \frac{1}{R^{k}} \bar{E}_{t}\left(\boldsymbol{\theta}_{t+1+k}\right)-\gamma \boldsymbol{\Sigma}_{\theta, t} \mathbf{S}_{t}\right\}+\frac{1}{R}\left\{\Delta_{t}-\gamma \boldsymbol{\Sigma}_{\Delta, t} \mathbf{S}_{t}\right\}
$$

The first term in (23) corresponds to prices in traditional asset pricing models where HOB reduce to expectations about fundamentals, adjusted for risk (as is the case when $T=1$ in our model), while the second term captures the difference between our model and present value models due to the effects of HOB. Equation (23) can be used to show how our model incorporates several previous theories of financial contagion, including the effect of past losses on investors' risk aversion (Kyle and Xiong, 2001 and Goldstein and Pauzner, 2004), rational confusion (Calvo, 1999) and the role of information markets in generating comovement (Veldkamp, 2005). ${ }^{18}$

\footnotetext{
${ }^{16}$ See e.g. Forbes and Rigobon (2002).

${ }^{17}$ Even if asset price comovement as measured by price correlations increases in times of market turmoil, there is ample evidence of excess comovement in tranquil times as well (see the references listed in the previous subsection).

${ }^{18}$ Further interesting theories of financial contagion include Calvo and Mendoza (2000), Allen and Gale (2000),
} 
A popular theory of contagion is rational confusion: liquidity shocks will affect prices, and rational investors who use prices to update their expectations of fundamentals will attribute the resulting price change partly to a change in fundamentals. This channel magnifies the effects of liquidity shocks and is at the heart of Calvo's (1999) explanation of sudden outflows of capital in times of crisis. In our framework, both $\bar{E}_{t}\left(\boldsymbol{\theta}_{t+k}\right)$ and $\Delta_{t}$ will be affected by liquidity shocks, as investors use the observed prices (current and past) to extract information about the private signals of other investors. Because prices are observed by everyone in the market, HOB will place more weight on them than standard average expectations. Therefore we have $\partial \Delta_{t} / \partial \mathbf{s}_{t}>0$, so that HOB will magnify the effects of liquidity shocks through the rational confusion channel. Similarly, the spillover effects in King and Wadhwani's (1990) study of stock market comovement, where uninformed investors extract information from asset prices in a foreign market, would be magnified when HOB are taken into account.

In Veldkamp (2006) many investors endogenously choose to purchase the same information which is valuable for forecasting the returns of many assets, generating 'excessive' price covariances. The static model in Veldkamp (2006) could be extended to a dynamic setting where HOB would arise similarly to our model. If investors had access to private information, and if both this private information and the signals purchased on information markets stayed informative for at least two periods, HOB would magnify asset price comovement. Thus the presence of information markets in Veldkamp (2006) leads to excess comovement, which is further magnified by HOB.

Kyle and Xiong (2001) and Goldstein and Pauzner (2004) argue that past losses may result in an increase in investors' risk aversion, thus transmitting shocks. This can be achieved in our setup by letting the coefficient of absolute risk aversion $\gamma$ become an increasing function of past losses. In our numerical simulations the elements in the matrix $\boldsymbol{\Sigma}_{\Delta, t}$ are generally negative. Intuitively, next period's prices are less uncertain than future fundamentals because prices are affected by public information which is at least partly known today. Therefore both variances and covariances of asset payoffs are smaller when HOB are taken into account: the presence of HOB will decrease the effect of past losses on risk aversion, making this transmission channel less important.

\subsection{Policy implications}

With an increasingly integrated financial system, the risk that shocks from foreign markets are transmitted across markets and affect the domestic financial system has risen. For policymakers it is important to understand the transmission channels through which such financial contagion occurs as this can help in estimating the probability that risks materialize, and to take appropriate policy responses. This paper suggests that the presence of higher order beliefs can magnify the impact of public information across markets. Therefore, the impact of possible negative information - for example, a credit rating downgrade - may be larger than expected based on the relationship of the markets affected. This result holds even in the absence of

Kodres and Pritsker (2002), and Chari and Kehoe (2003). 
financial frictions, and with fully rational investors.

The main policy implication of our analysis concerns the benefits of transparency. Recall from Figure 2, panel (b) that asset price correlation becomes more excessive as the variance of public information rises. To the extent that excessive comovement is economically undesirable, this result highlights the benefits of providing accurate public information. ${ }^{19}$ Since policymakers' actions, for example interest rate decisions of central banks, also convey information to the public, our results suggest that transparency is useful to limit excessive comovement: policymakers should communicate the motives behind their actions to the public and should strive to be understood by market participants.

\section{Conclusion}

This paper analyzes the role of higher-order expectations in markets with multiple risky assets. When speculation is an important motive for trading financial assets, prices are influenced by expectations about the expectations of future investors. In such higher order expectations more weight is given to public information. We show that this feature generates excess comovement - information spillovers across prices and price correlations that are higher than justified by the comovement of underlying fundamentals. Thus the presence of higher order beliefs can potentially explain the seemingly 'excessive' asset price comovement observed in financial markets.

To the best of our knowledge, this paper is the first to analyze the effects of higher order beliefs on asset price comovement. We develop a dynamic asset pricing model with multiple risky securities where higher order beliefs arise because investors need to forecast future prices. The model nests several previous theories of financial market comovement. While some transmission channels highlighted in the previous literature are magnified by higher-order beliefs, other channels become less important when higher-order beliefs are taken into account.

Empirical studies on excess comovement typically regress asset prices on measures of economic fundamentals, and interpret the finding that the covariances of the residuals from this regression are non-zero as 'excess comovement'. However, this finding is consistent with the standard present value model where asset prices are determined by expected discounted future cashflows: when fundamentals are related across assets, each asset price is affected by the same information and hence information errors generate comovement. Our central result is that the presence of higher order beliefs magnifies this comovement because investors place more weight on public information. We show that depending on the underlying parameter values - especially if public information is very noisy and stays informative for a long time - the increase in correlation due to higher order expectations can be large. Therefore higher order beliefs can contribute to explaining the high degree of comovement found in empirical studies. Allowing for a realistic information structure generates excess comovement, without the need for assuming

\footnotetext{
${ }^{19}$ Morris and Shin (2002) argue that increased transparency could actually be detrimental to welfare when agents may coordinate on a 'bad' signal. In our model simulations show that the effect of public information accuracy on the spillover of public information noise is ambiguous, while the amount of excess correlation is always decreasing in public information accuracy.
} 
financial frictions or irrational behavior.

Although the analytical results in this paper are derived in a highly stylized model, we show in numerical simulations that the main results carry over to a fairly general asset pricing framework. Details of the market structure may affect the quantitative importance of our results, but the main result that higher order beliefs are associated with excessive comovement in markets with multiple risky assets appears to be robust.

\section{References}

[1] Admati, Anat R. (1985), "A Noisy Rational Expectations Equilibrium for Multi-Asset Securities Markets," Econometrica 53(3), pp. 629-657.

[2] Allen, Franklin and Douglas Gale (2000), "Financial Contagion," Journal of Political Economy 108(1), pp. 1-33.

[3] Allen, Franklin, Stephen Morris and Hyun S. Shin (2006), "Beauty Contests and Iterated Expectations in Asset Markets," Review of Financial Studies 13(3), pp. 719-752.

[4] Bacchetta, Philippe and Eric van Wincoop (2003), "Can Information Heterogeneity Explain the Exchange Rate Determination Puzzle?" NBER Working Paper No. 9498.

[5] Bacchetta, Philippe and Eric van Wincoop (2006), "Can Information Heterogeneity Explain the Exchange Rate Determination Puzzle?" American Economic Review 96(3), pp. 552576 .

[6] Bacchetta, Philippe and Eric van Wincoop (2007), "Higher Order Expectations in Asset Pricing," mimeo, Study Center Gerzensee and University of Virginia.

[7] Barberis, Nicholas and Andrei Shleifer (2005), "Comovement", Journal of Financial Economics 75(2), pp. 283-317.

[8] Beltratti, Andrea E. and Robert J. Shiller (1993), "Actual and Warranted Relations Between Asset Prices," Oxford Economic Papers 45(3), pp. 387-402.

[9] Calvo, Guillermo (1999), "Contagion in Emerging Markets: When Wall Street is the Carrier," Working Paper, University of Maryland.

[10] Calvo, Guillermo and Enrique Mendoza (2000), "Rational Contagion and the Globalization of Securities Markets," Journal of International Economics 51(1), pp. 79-113.

[11] Chari, Varadarajan and Patrick J. Kehoe (2003), "Hot Money," Journal of Political Economy 111(6), pp. 1262-1292.

[12] Deb, Partha, Pravin K. Trivedi and Panayotis Varangis (1996), "The Excess Co-Movement of Commodity Prices Reconsidered," Journal of Applied Econometrics 11(3), pp. 275-291.

[13] Engsted, Tom and Carsten Tanggaard (2004), "The Comovement of US and UK Stock Markets," European Financial Markets 10(4), pp. 593-607.

[14] Forbes, Kristin and Roberto Rigobon (2002), "No Contagion, only Interdependence," Journal of Finance 57(5), pp. 2223-2261. 
[15] Goldstein, Itay and Ady Pauzner (2004), "Contagion of Self-Fulfilling Financial Crises Due to Diversification of Investment Portfolios," Journal of Economic Theory 119(1), pp. 151-183.

[16] Hussman, John P. (1992), "Differential Information and Dynamic Behavior of Stock Trading Volume," Journal of Economic Dynamics and Control 16(3-4), pp. 655-680.

[17] Kallberg, Jarl and Paolo Pasquariello (2007), "Time-Series and Cross-Sectional Excess Comovement in Stock Indexes," Journal of Empirical Finance, forthcoming.

[18] Keynes, John M. (1936), The General Theory of Employment, Interest and Money. London: Macmillan.

[19] King, Mervyn A. and Sushil Wadhwani (1990), "Transmission of Volatility Between Stock Markets," Review of Financial Studies 3(1), pp. 5-33.

[20] Kodres, Laura E., and Matt Pritsker (2002), "A Rational Expectations Model of Financial Contagion," Journal of Finance 57(2), pp. 769-799.

[21] Kyle, Albert S. and Wei Xiong (2001), "Contagion as a Wealth Effect," Journal of Finance 56(4), pp. 1401-1440.

[22] Lorenzoni, Guido (2006), "A Theory of Demand Shocks," mimeo, MIT.

[23] Monnin, Pierre (2005), "Are Stock Markets Really Like Beauty Contests?" mimeo, Swiss National Bank and University of Zürich.

[24] Morris, Stephen and Hyun S. Shin (2002), "The Social Value of Public Information," American Economic Review 92(5), pp.1521-1534.

[25] Nimark, Kristoffer P. (2007), "Dynamic Pricing and Imperfect Common Knowledge," Journal of Monetary Economics, forthcoming.

[26] Pagratis, Spyros (2005), "Asset Pricing, Asymmetric Information and Rating Announcements: Does Benchmarking on Ratings Matter?", Bank of England WP No. 265.

[27] Pindyck, Robert S. and Julio J. Rotemberg (1990), "The Excess Co-Movement of Commodity Prices," Economic Journal 100(403) pp. 1173-1189.

[28] Pindyck, Robert S. and Julio J. Rotemberg (1993), "The Comovement of Stock Prices," Quarterly Journal of Economics 108(4), pp. 1073-1104.

[29] Shiller, Robert J. (1989), "Comovements in Stock Prices and Comovements in Dividends," Journal of Finance 44(3), pp. 719-729.

[30] Singleton, Kenneth J. (1987), "Asset Prices in a Time-Series Model with Disparately Informed, Competitive Traders," in New Approaches to Monetary Economics, Proceedings of the Second International Symposium in Economic Theory and Econometrics, W.A. Barnet and K.J. Singleton (eds), Cambridge University Press, pp. 249-271.

[31] Sutton, Gregory D. (2000), "Is There Excess Co-movement of Bond Yields Between Countries?" Journal of International Money and Finance 19(3), pp. 363-376.

[32] Townsend, Robert M. (1983), "Forecasting the Forecasts of Others," Journal of Political Economy 91(4), pp. 546-588. 
[33] Veldkamp, Laura (2006), "Information Markets and the Comovement of Asset Prices," Review of Economic Studies 73(3), pp. 823-845.

[34] Woodford, Michael (2003), "Imperfect Common Knowledge and the Effects of Monetary Policy," in Knowledge, Information and Expectations in Modern Macroeconomics: In Honor of Edmund S. Phelps, P. Aghion, R. Frydman, J. Stiglitz and M. Woodford (eds), Princeton University Press, pp. 25-58.

[35] Zhou, Chunsheng (1998), "Dynamic Portfolio Choice and Asset Pricing with Differential Information," Journal of Economic Dynamics and Control 22(7), pp. 1027-1051. 


\section{Appendices}

\section{A Coefficients of average expectations for the special case}

For notational convenience let $\alpha_{j} \equiv 1 / \sigma_{\theta j}^{2}, \beta_{j} \equiv 1 / \sigma_{x j}^{2}, \delta_{j} \equiv 1 / \sigma_{z j}^{2}$ denote respectively the precisions of fundamentals, private and public information, for $j=1,2$. Then in equation (5) and (6) the weights placed on different sources of information in the formation of expectations about $\theta_{i}$ are given by

$$
\begin{aligned}
a_{i i} & =\frac{\alpha_{i}\left(\alpha_{j}+\beta_{j}+\delta_{j}\right)}{\left(\alpha_{1}+\beta_{1}+\delta_{1}\right)\left(\alpha_{2}+\beta_{2}+\delta_{2}\right)-\alpha_{1} \alpha_{2}\left(\beta_{1}+\delta_{1}\right)\left(\beta_{2}+\delta_{2}\right) \rho^{2}} \\
a_{i j} & =\frac{-\alpha_{1} \alpha_{2}\left(\beta_{j}+\delta_{j}\right) \rho}{\left(\alpha_{1}+\beta_{1}+\delta_{1}\right)\left(\alpha_{2}+\beta_{2}+\delta_{2}\right)-\alpha_{1} \alpha_{2}\left(\beta_{1}+\delta_{1}\right)\left(\beta_{2}+\delta_{2}\right) \rho^{2}}<0 \\
b_{i i} & =\frac{\beta_{i}\left[\left(\alpha_{j}+\beta_{j}+\delta_{j}\right)-\alpha_{1} \alpha_{2}\left(\beta_{j}+\delta_{j}\right) \rho^{2}\right]}{\left(\alpha_{1}+\beta_{1}+\delta_{1}\right)\left(\alpha_{2}+\beta_{2}+\delta_{2}\right)-\alpha_{1} \alpha_{2}\left(\beta_{1}+\delta_{1}\right)\left(\beta_{2}+\delta_{2}\right) \rho^{2}} \\
b_{i j} & =\frac{\alpha_{1} \alpha_{2} \beta_{j} \rho}{\left(\alpha_{1}+\beta_{1}+\delta_{1}\right)\left(\alpha_{2}+\beta_{2}+\delta_{2}\right)-\alpha_{1} \alpha_{2}\left(\beta_{1}+\delta_{1}\right)\left(\beta_{2}+\delta_{2}\right) \rho^{2}} \\
c_{i i} & =\frac{\delta_{i}\left[\left(\alpha_{j}+\beta_{j}+\delta_{j}\right)-\alpha_{1} \alpha_{2}\left(\beta_{j}+\delta_{j}\right) \rho^{2}\right]}{\left(\alpha_{1}+\beta_{1}+\delta_{1}\right)\left(\alpha_{2}+\beta_{2}+\delta_{2}\right)-\alpha_{1} \alpha_{2}\left(\beta_{1}+\delta_{1}\right)\left(\beta_{2}+\delta_{2}\right) \rho^{2}} \\
c_{i j} & =\frac{\alpha_{1} \alpha_{2} \delta_{j} \rho}{\left(\alpha_{1}+\beta_{1}+\delta_{1}\right)\left(\alpha_{2}+\beta_{2}+\delta_{2}\right)-\alpha_{1} \alpha_{2}\left(\beta_{1}+\delta_{1}\right)\left(\beta_{2}+\delta_{2}\right) \rho^{2}}
\end{aligned}
$$

for $i, j=1,2$ with $i \neq j$.

The common denominator of the above coefficients is positive, which implies that $a_{12}$ and $a_{21}$ are negative while all other coefficients are positive. To see this let $C^{2}=\alpha_{1} \alpha_{2} \rho^{2}$ denote the square of the correlation of shocks to fundamentals, $\varepsilon_{1}$ and $\varepsilon_{2}$. Then the common denominator is positive if

$$
\left(\alpha_{1}+\beta_{1}+\delta_{1}\right)\left(\alpha_{2}+\beta_{2}+\delta_{2}\right)>\left(\beta_{1}+\delta_{1}\right)\left(\beta_{2}+\delta_{2}\right) C^{2}
$$

which holds since $C^{2} \in[0,1]$.

\section{B Proofs}

\section{Proof of proposition 2.}

Unlike in the case of proposition 1, it is not directly clear from the difference equations in (17) that $b_{1 t}^{1 *}$ and $b_{2 t}^{2 *}$ increase over time. To show that this is indeed the case, the difference equations for the coefficients $b_{1 t}^{1 *}$ and $b_{2 t}^{2 *}$ need to be solved. Equations (17) and (18) can be written as

$$
\left[\begin{array}{l}
b_{1 t-1}^{j *} \\
b_{2 t-1}^{j *}
\end{array}\right]=\left[\begin{array}{ll}
b_{11} & b_{21} \\
b_{12} & b_{22}
\end{array}\right] \cdot\left[\begin{array}{c}
b_{1 t}^{j *} \\
b_{2 t}^{j *}
\end{array}\right]
$$

with initial conditions $b_{j \bar{T}}^{i *}=b_{i j}$. Substituting from equations (26) and (27) one can show that $b_{11} b_{22}-b_{21} b_{12}>0$, so that the matrix in equation (30) is invertible. The solutions to this 
system of difference equations are

$$
\begin{aligned}
b_{1 t}^{1 *} & =-e_{1} \frac{b_{12} \lambda_{2}}{\lambda_{1}-\lambda_{2}} \cdot\left(\frac{1}{\lambda_{1}}\right)^{\bar{T}-t}+e_{2} \frac{b_{12} \lambda_{1}}{\lambda_{1}-\lambda_{2}} \cdot\left(\frac{1}{\lambda_{2}}\right)^{\bar{T}-t} \\
b_{2 t}^{1 *} & =-\frac{b_{12} \lambda_{2}}{\lambda_{1}-\lambda_{2}} \cdot\left(\frac{1}{\lambda_{1}}\right)^{\bar{T}-t}+\frac{b_{12} \lambda_{1}}{\lambda_{1}-\lambda_{2}} \cdot\left(\frac{1}{\lambda_{2}}\right)^{\bar{T}-t}
\end{aligned}
$$

and

$$
\begin{aligned}
b_{1 t}^{2 *} & =e_{1} \frac{1-\lambda_{2} b_{22}}{\lambda_{1}-\lambda_{2}} \cdot\left(\frac{1}{\lambda_{1}}\right)^{\bar{T}-t}-e_{2} \frac{1-\lambda_{1} b_{22}}{\lambda_{1}-\lambda_{2}} \cdot\left(\frac{1}{\lambda_{2}}\right)^{\bar{T}-t} \\
b_{2 t}^{2 *} & =\frac{1-\lambda_{2} b_{22}}{\lambda_{1}-\lambda_{2}} \cdot\left(\frac{1}{\lambda_{1}}\right)^{\bar{T}-t}-\frac{1-\lambda_{1} b_{22}}{\lambda_{1}-\lambda_{2}} \cdot\left(\frac{1}{\lambda_{2}}\right)^{\bar{T}-t}
\end{aligned}
$$

where $\lambda_{j}$ are the eigenvalues and $e_{j}$ the non-normalized elements of the corresponding eigenvectors of the system. Using the expressions for coefficients $b_{11}, b_{12}, b_{21}$ and $b_{22}$ in appendix A we find that $\lambda_{1}>\lambda_{2}>1$ and $e_{1}<0, e_{2}>0$. Proposition 2 then follows directly from equations (31) and (34). Q.E.D.

\section{Conditions for excessive covariance.}

The following proposition is a preliminary step for the proof of proposition three.

Proposition 4 (Sufficient conditions for excessive covariance)

Let $\operatorname{cov}\left(\bar{E}_{t} \ldots \bar{E}_{\bar{T}}\left(\theta_{1}\right), \bar{E}_{t} \ldots \bar{E}_{\bar{T}}\left(\theta_{2}\right) \mid \theta_{1}, \theta_{2}\right)$ denote the covariance of higher order expectations about fundamentals $\theta_{1}$ and $\theta_{2}$, conditional on $\theta_{1}$ and $\theta_{2}$; and let $\operatorname{cov}\left(\bar{E}_{t}\left(\theta_{1}\right), \bar{E}_{t}\left(\theta_{2}\right) \mid \theta_{1}, \theta_{2}\right)$ denote the covariance of average expectations about fundamentals $\theta_{1}$ and $\theta_{2}$, conditional on $\theta_{1}$ and $\theta_{2}$. Then a sufficient condition for

$$
\operatorname{cov}\left(\bar{E}_{t} \ldots \bar{E}_{\bar{T}}\left(\theta_{1}\right), \bar{E}_{t} \ldots \bar{E}_{\bar{T}}\left(\theta_{2}\right) \mid \theta_{1}, \theta_{2}\right)>\operatorname{cov}\left(\bar{E}_{t}\left(\theta_{1}\right), \bar{E}_{t}\left(\theta_{2}\right) \mid \theta_{1}, \theta_{2}\right)
$$

to hold is that

$$
\beta_{1} \beta_{2}<\delta_{1} \delta_{2}+\frac{\alpha_{1} \alpha_{2}+\alpha_{2} \delta_{2}+\alpha_{1} \delta_{1}}{1-C^{2}}
$$

where $C^{2} \equiv \alpha_{1} \alpha_{2} \rho^{2}$. Moreover, in the limit as $\bar{T}-t \rightarrow \infty$, (35) will always hold.

\section{Proof.}

The strategy for this proof is as follows. First, we prove several relationships between the HOBcoefficients, which will help us to considerably simplify the expression for the covariance. We then find an expression that describes how this simplified covariance depends on time. Finally, we show that the covariance decreases for all periods if the covariance of average expectations is positive.

We begin by proving the following lemma, which describes some interesting relationships between the weights placed on different sources of information in the formation of higher-order beliefs. 
Lemma 5 We have

$$
\begin{aligned}
& \frac{a_{1 t}^{1 *}}{\alpha_{1}}=\frac{c_{1 t}^{1 *}}{\delta_{1}}-a_{2 t}^{1 *} \rho \\
& \frac{a_{2 t}^{1 *}}{\alpha_{1}}=\frac{c_{2 t}^{1 *}}{\delta_{1}}-a_{1 t}^{1 *} \rho \\
& \frac{a_{1 t}^{2 *}}{\alpha_{1}}=\frac{c_{1 t}^{2 *}}{\delta_{1}}-a_{2 t}^{2 *} \rho \\
& \frac{a_{2 t}^{2 *}}{\alpha_{2}}=\frac{c_{2 t}^{2 *}}{\delta_{2}}-a_{1 t}^{2 *} \rho
\end{aligned}
$$

Proof. The proof is by backward induction from the final period $t=\bar{T}$. For the inductive step, it is easily verified from equations (24) to (29) in appendix A that (37) to (40) hold in period $\bar{T}$.

Next we show that if (37) to (40) hold for period $t$, they will also hold in $t-1$. Begin with (37), and assume that (37) holds in $t$. Dividing (13), the difference equation for $a_{1 t}^{1 *}$, by $\alpha_{1}$ and using (37), (15) and (14), we have

$$
\begin{aligned}
\frac{a_{1 t-1}^{1 *}}{\alpha_{1}} & =\frac{a_{1 t}^{1 *}}{\alpha_{1}}+b_{1 t}^{1 *} \frac{a_{11}}{\alpha_{1}}+b_{2 t}^{1 *} \frac{a_{21}}{\alpha_{1}} \\
& =\left(\frac{c_{1 t}^{1 *}}{\delta_{1}}-a_{2 t}^{1 *} \rho\right)+b_{1 t}^{1 *} \frac{a_{12}}{\alpha_{1}}+b_{2 t}^{1 *} \frac{a_{22}}{\alpha_{1}} \\
& =\frac{c_{1 t-1}^{1 *}-b_{1 t}^{1 *} c_{11}-b_{2 t}^{1 *} c_{21}}{\delta_{1}}-\left(a_{2 t-1}^{1 *}-b_{1 t}^{1 *} a_{12}+b_{2 t}^{1 *} a_{22}\right) \rho+b_{1 t}^{1 *} \frac{a_{12}}{\alpha_{1}}+b_{2 t}^{1 *} \frac{a_{22}}{\alpha_{1}} \\
& =\frac{c_{1 t-1}^{1 *}}{\delta_{1}}-a_{2 t-1}^{1 *} \rho+b_{1 t}^{1 *}\left(\frac{a_{11}}{\alpha_{1}}-\frac{c_{11}}{\delta_{1}}+a_{12} \rho\right)+b_{2 t}^{1 *}\left(\frac{a_{21}}{\alpha_{1}}-\frac{c_{21}}{\delta_{1}}+a_{22} \rho\right)
\end{aligned}
$$

We have shown that (37) holds for $t=\bar{T}$, so that the terms in parentheses are zero which gives our result. The proofs of (38) to (40) are similar and therefore omitted.

Lemma 6 We have

$$
\begin{aligned}
\frac{c_{2 t}^{1 *}}{\delta_{2}} & =\frac{c_{1 t}^{2 *}}{\delta_{1}} \\
\frac{b_{2 t}^{1 *}}{\beta_{2}} & =\frac{b_{1 t}^{2 *}}{\beta_{1}}
\end{aligned}
$$

Proof. The proof is by induction from $\bar{T}$. For $t=\bar{T}$, we can verify from the expressions of the coefficients in appendix A that (41) and (42) indeed hold. Next, suppose that both relationships hold for some period $t$. Using the difference equations in appendix B, (41) then also holds in $t-1$ if

$$
\frac{c_{2 t}^{1 *}+b_{1 t}^{1 *} c_{12}+b_{2 t}^{1 *} c_{22}}{\delta_{2}}=\frac{c_{1 t}^{2 *}+b_{1 t}^{2 *} c_{11}+b_{2 t}^{2 *} c_{21}}{\delta_{1}}
$$

Noting that (41) holds in $t$ and that (42) holds in $\bar{T}$ and making use of the fact that $b_{22} \delta_{2}=c_{22} \beta_{2}$ and canceling out terms produces

$$
\frac{b_{1 t}^{1 *}-b_{2 t}^{2 *}}{b_{11}-b_{22}}=\frac{b_{1 t}^{2 *}}{b_{21}}
$$


Similarly, given that (42) holds in $t$, it will hold for $t-1$ as well if

$$
\frac{b_{1 t}^{1 *}-b_{2 t}^{2 *}}{b_{11}-b_{22}}=\frac{b_{2 t}^{1 *}}{b_{12}}
$$

Thus we need to prove that

$$
\frac{b_{1 t}^{1 *}-b_{2 t}^{2 *}}{b_{11}-b_{22}}=\frac{b_{1 t}^{2 *}}{b_{21}}=\frac{b_{2 t}^{1 *}}{b_{12}}
$$

holds for all $t$. This is again done by backward induction. For $t=\bar{T}$, it can be verified from appendix A that (43) holds. Next, suppose (43) holds for some $t$. Then for $t-1$ we require

$$
\begin{aligned}
b_{21}\left(b_{1 t-1}^{1 *}-b_{2 t-1}^{2 *}\right) & =b_{1 t-1}^{2 *}\left(b_{11}-b_{22}\right) \\
b_{21}\left[\left(b_{1 t}^{1 *} b_{11}+b_{2 t}^{1 *} b_{21}\right)-\left(b_{1 t}^{2 *} b_{12}+b_{2 t}^{2 *} b_{22}\right)\right] & =\left(b_{1 t}^{2 *} b_{11}+b_{2 t}^{2 *} b_{21}\right)\left(b_{11}-b_{22}\right)
\end{aligned}
$$

Making use of the fact that (42) holding in period $t$ implies that $b_{2 t}^{1 *} b_{21}=b_{1 t}^{2 *} b_{12}$ and canceling out terms we have

$$
\frac{b_{1 t}^{1 *}-b_{2 t}^{2 *}}{b_{11}-b_{22}}=\frac{b_{1 t}^{2 *}}{b_{21}}
$$

which holds for $t$ as postulated.

From equation (11) and (12), we can compute the covariance of higher order expectations, conditional on the true realization of fundamentals $\theta_{1}$ and $\theta_{2}$ as

$$
\operatorname{Cov}\left[E_{s}\left(\theta_{1}\right), E_{s}\left(\theta_{2}\right) \mid \theta_{1}, \theta_{2}\right]=\frac{a_{1 t}^{1 *} a_{1 t}^{2 *}}{\alpha_{1}}+\frac{a_{2 t}^{1 *} a_{2 t}^{2 *}}{\alpha_{2}}+\frac{c_{1 t}^{1 *} c_{1 t}^{2 *}}{\delta_{1}}+\frac{c_{2 t}^{1 *} c_{2 t}^{2 *}}{\delta_{2}}+\left(a_{1 t}^{1 *} a_{2 t}^{2 *}+a_{2 t}^{1 *} a_{1 t}^{2 *}\right) \rho
$$

Using equations (39) and (40) we can simplify this expression as follows:

$$
\begin{aligned}
\operatorname{Cov}\left[E_{s}\left(\theta_{1}\right), E_{s}\left(\theta_{2}\right) \mid \theta_{1}, \theta_{2}\right]= & a_{1 t}^{1 *}\left(\frac{c_{1 t}^{2 *}}{\delta_{1}}-a_{2 t}^{2 *} \rho\right)+a_{2 t}^{1 *}\left(\frac{c_{2 t}^{2 *}}{\delta_{2}}-a_{1 t}^{2 *} \rho\right) \\
& +\frac{c_{1 t}^{1 *} c_{1 t}^{2 *}}{\delta_{1}}+\frac{c_{2 t}^{1 *} c_{2 t}^{* *}}{\delta_{2}}+\left(a_{1 t}^{1 *} a_{2 t}^{2 *}+a_{2 t}^{1 *} a_{1 t}^{2 *}\right) \rho \\
= & \frac{\left(a_{1 t}^{1 *}+c_{1 t}^{1 *}\right) c_{1 t}^{2 *}}{\delta_{1}}+\frac{\left(a_{2 t}^{1 *}+c_{2 t}^{1 *}\right) c_{2 t}^{2 *}}{\delta_{2}} \\
= & \frac{\left(1-b_{1 t}^{1 *}\right) c_{1 t}^{2 *}}{\delta_{1}}-\frac{b_{2 t}^{1 *} c_{2 t}^{2 *}}{\delta_{2}}
\end{aligned}
$$

Finally using equation (41), this can be further simplified to

$$
\operatorname{Cov}\left[E_{s}\left(\theta_{1}\right), E_{s}\left(\theta_{2}\right) \mid \theta_{1}, \theta_{2}\right]=\frac{\left(1-b_{1 t}^{1 *}\right) c_{2 t}^{1 *}-b_{2 t}^{1 *} c_{2 t}^{2 *}}{\delta_{2}}
$$

In the final period $t=\bar{T}$, this will boil down to the covariance of average expectations, given by

$$
\operatorname{Cov}\left[\bar{E}_{t}\left(\theta_{1}\right), \overline{E_{t}}\left(\theta_{2}\right) \mid \theta_{1}, \theta_{2}\right]=\frac{\left(1-b_{11}\right) c_{12}-b_{12} c_{22}}{\delta_{1}}
$$

We can then use the difference equations in appendix B to express the equation (44) as a 
function of time. Leaving out the (constant) denominator $\delta_{2}$, after some tedious algebra we get

$$
\begin{aligned}
\operatorname{Cov}\left[\bar{E}_{t}^{s}\left(\theta_{1}\right), \bar{E}_{t}^{s}\left(\theta_{2}\right) \mid \theta_{1}, \theta_{2}\right]= & C_{0}+C_{1} \cdot\left(\frac{1}{\lambda_{1}}\right)^{s}-C_{2} \cdot\left(\frac{1}{\lambda_{2}}\right)^{s}-\ldots \\
& \ldots-C_{11} \cdot\left(\frac{1}{\lambda_{1}}\right)^{2 s}+C_{22} \cdot\left(\frac{1}{\lambda_{2}}\right)^{2 s}
\end{aligned}
$$

where $s=\bar{T}-t$ and

$$
\begin{aligned}
C_{0} & =c_{12}-\frac{c_{12}}{\lambda_{1}-\lambda_{2}}\left(\frac{\lambda_{1}}{1-\lambda_{2}}-\frac{\lambda_{2}}{1-\lambda_{1}}\right) \\
C_{1} & =-2 \frac{c_{12}}{\lambda_{1}-\lambda_{2}} \frac{\lambda_{2}}{1-\lambda_{1}}>0 \\
& =\frac{c_{12}}{1-\left(b_{11}+b_{22}\right)+\left(b_{11} b_{22}-b_{21} b_{12}\right)}>c_{12} \\
C_{2} & =-2 \frac{c_{12}}{\lambda_{1}-\lambda_{2}} \frac{\lambda_{1}}{1-\lambda_{2}}>0 \\
C_{11} & =-\frac{c_{12}}{\lambda_{1}-\lambda_{2}} \frac{\lambda_{2}}{\lambda_{1}\left(1-\lambda_{1}\right)}>0 \\
C_{22} & =-\frac{c_{12}}{\lambda_{1}-\lambda_{2}} \frac{\lambda_{1}}{\lambda_{2}\left(1-\lambda_{2}\right)}>0
\end{aligned}
$$

The idea of the proof then is to show that the covariance of higher-order beliefs decreases over time, or increases in $s$, provided that the covariance of average expectations is positive. From equation (45) and rearranging, the covariance of HOB increases from period $s$ to $s+1$ if

$$
\begin{array}{r}
\left(\frac{1}{\lambda_{2}}\right)^{s}\left(1-\frac{1}{\lambda_{2}}\right) \cdot\left\{C_{2}-C_{22}\left(\frac{1}{\lambda_{2}}\right)^{s}\left(\frac{1}{\lambda_{2}}+1\right)\right\} \\
>\quad\left(\frac{1}{\lambda_{1}}\right)^{s}\left(1-\frac{1}{\lambda_{1}}\right) \cdot\left\{C_{1}-C_{11}\left(\frac{1}{\lambda_{1}}\right)^{s}\left(\frac{1}{\lambda_{1}}+1\right)\right\}
\end{array}
$$

which can be split in two sufficient conditions:

$$
\begin{aligned}
&\left(\frac{1}{\lambda_{2}}\right)^{s}\left(1-\frac{1}{\lambda_{2}}\right)>\left(\frac{1}{\lambda_{1}}\right)^{s}\left(1-\frac{1}{\lambda_{1}}\right) \\
& C_{2}-C_{22}\left(\frac{1}{\lambda_{2}}\right)^{s}\left(\frac{1}{\lambda_{2}}+1\right)>C_{1}-C_{11}\left(\frac{1}{\lambda_{1}}\right)^{s}\left(\frac{1}{\lambda_{1}}+1\right)
\end{aligned}
$$

In the following we show that (46) holds for $s \geq 1$ and (47) holds for all $s$, provided that the covariance of average expectations is positive, for all $s \geq 1$.

The proof of (46) is by induction from $s=1$. Since $\lambda_{1}>\lambda_{2}>1$, it is easy to see that (46) will hold for $s+1$, provided that it holds for $s$. Furthermore, for $s=1$ we have

$$
\frac{1}{\lambda_{2}}\left(1-\frac{1}{\lambda_{2}}\right)>\frac{1}{\lambda_{1}}\left(1-\frac{1}{\lambda_{1}}\right)
$$

or equivalently

$$
\lambda_{1} \lambda_{2}>\lambda_{1}+\lambda_{2}
$$


Substituting for the eigenvalues, we find that this condition is equal to

$$
1>b_{11}+b_{22}
$$

Now notice that the covariance of average expectations is given by

$$
\begin{aligned}
\operatorname{Cov}\left[\bar{E}_{t}\left(\theta_{1}\right), \overline{E_{t}}\left(\theta_{2}\right) \mid \theta_{1}, \theta_{2}\right] & =\frac{\left(1-b_{11}\right) c_{12}-b_{12} c_{22}}{\delta_{1}} \\
& =\frac{\left(1-b_{11}-b_{22}\right) c_{12}}{\delta_{1}}
\end{aligned}
$$

since $b_{12} c_{22}=c_{12} b_{22}$. Therefore, a sufficient condition for (46) to hold is that the covariance of average expectations is positive. This proves that (46) holds for $s \geq 1$.

Sufficient condition (47) requires

$$
\left[C_{2}-C_{1}\right]-\left[C_{22}\left(\frac{1}{\lambda_{2}}\right)^{s}\left(\frac{1}{\lambda_{2}}+1\right)-C_{11}\left(\frac{1}{\lambda_{1}}\right)^{s}\left(\frac{1}{\lambda_{1}}+1\right)\right]>0
$$

One can show that both terms in square brackets are positive. Furthermore, by induction from $s=0$ one can show that the second term is decreasing in $s$. Therefore, it is sufficient to show that the above expression is positive for $s=0$, which requires

$$
\left[C_{2}-C_{1}\right]-\left[C_{22}\left(\frac{1}{\lambda_{2}}+1\right)-C_{11}\left(\frac{1}{\lambda_{1}}+1\right)\right]>0
$$

Substituting we get

$$
2\left(\lambda_{1}\right)^{2}\left(\lambda_{2}\right)^{2}\left(\lambda_{1}-\lambda_{2}\right)\left[\left(\lambda_{1}+\lambda_{2}\right)-1\right]>\left(\lambda_{1} \lambda_{2}-1\right)\left[\left(\lambda_{1}\right)^{3}-\left(\lambda_{2}\right)^{3}\right]+\left(\lambda_{1}-\lambda_{2}\right)\left[\left(\lambda_{1}\right)^{3}+\left(\lambda_{2}\right)^{3}\right]
$$

which can be split into two further sufficient conditions:

$$
\begin{aligned}
& \left(\lambda_{1}\right)^{2}\left(\lambda_{2}\right)^{2}\left(\lambda_{1}-\lambda_{2}\right)\left[\left(\lambda_{1}+\lambda_{2}\right)-1\right]>\left[\left(\lambda_{1}\right)^{3}+\left(\lambda_{2}\right)^{3}\right]\left(\lambda_{1}-\lambda_{2}\right) \\
& \left(\lambda_{1}\right)^{2}\left(\lambda_{2}\right)^{2}\left(\lambda_{1}-\lambda_{2}\right)\left[\left(\lambda_{1}+\lambda_{2}\right)-1\right]>\left[\left(\lambda_{1}\right)^{3}-\left(\lambda_{2}\right)^{3}\right]\left(\lambda_{1} \lambda_{2}-1\right)
\end{aligned}
$$

Some algebra shows that a positive covariance of average expectations, implying $\lambda_{1} \lambda_{2}>\lambda_{1}+\lambda_{2}$, is sufficient for both conditions to hold.

Finally, expressing the covariance of average expectations in terms of the underlying parameters, we see that the covariance of average expectations is positive provided that

$$
\beta_{1} \beta_{2}<\delta_{1} \delta_{2}+\frac{\alpha_{1} \alpha_{2}+\alpha_{2} \delta_{2}+\alpha_{1} \delta_{1}}{1-C^{2}}
$$

Q.E.D.

The sufficient condition requires that the precision of public information (from both $y_{j}$ and $z_{j}$ ) is above a certain threshold, compared to the precision of private information. Excess comovement arises because of over-reliance on public information. However if the precision of private information is too high, the weight that investors in the final period place on public information will be very small, and in the last trading periods the HOB effect may not be sufficient to generate excess comovement. In the long run, sufficiently far away from the final trading period $\bar{T}$, there will always be excessive comovement: as the order of HOB increases, so does the reliance on public information. Empirical studies typically find positive comovement 
after conditioning on fundamentals so that this condition seems to satisfied in practice.

\section{Proof of proposition 3.}

The strategy of this proof is first to use the relationships between the coefficients to find a simplified expression for the correlation; using this simplified expression, to derive two sufficient conditions for excessive correlation; and finally to express these sufficient conditions as functions of time and to show that they will hold for all time periods.

We begin by finding simplified expressions for the variances of expectations of assets one and two. Using the results in lemmata 8 and 9 , we have

$$
\begin{aligned}
\operatorname{Var}\left[\bar{E}_{t}^{s}\left(\theta_{1}\right) \mid \theta_{1}, \theta_{2}\right] & =\frac{\left(a_{1 t}^{1 *}\right)^{2}}{\alpha_{1}}+\frac{\left(a_{2 t}^{1 *}\right)^{2}}{\alpha_{2}}+2 a_{1 t}^{1 *} a_{2 t}^{1 *} \rho+\frac{\left(c_{1 t}^{1 *}\right)^{2}}{\delta_{1}}+\frac{\left(c_{2 t}^{1 *}\right)^{2}}{\delta_{2}} \\
& =\frac{c_{1 t}^{1 *}\left(1-b_{1 t}^{1 *}\right)-c_{1 t}^{2 *} b_{2 t}^{1 *}}{\delta_{1}}
\end{aligned}
$$

and

$$
\begin{aligned}
\operatorname{Var}\left[\bar{E}_{t}^{s}\left(\theta_{2}\right) \mid \theta_{1}, \theta_{2}\right] & =\frac{\left(a_{1 t}^{2 *}\right)^{2}}{\alpha_{1}}+\frac{\left(a_{2 t}^{2 *}\right)^{2}}{\alpha_{2}}+2 a_{1 t}^{2 *} a_{2 t}^{2 *} \rho+\frac{\left(c_{1 t}^{2 *}\right)^{2}}{\delta_{1}}+\frac{\left(c_{2 t}^{2 *}\right)^{2}}{\delta_{2}} \\
& =\frac{c_{2 t}^{2 *}\left(1-b_{2 t}^{2 *}\right)-c_{2 t}^{1 *} b_{1 t}^{2 *}}{\delta_{2}}
\end{aligned}
$$

Note also that the covariance can be written alternatively as

$$
\begin{aligned}
\operatorname{Cov}\left[\bar{E}_{t}^{s}\left(\theta_{1}\right), \bar{E}_{t}^{s}\left(\theta_{2}\right) \mid \theta_{1}, \theta_{2}\right] & =\frac{a_{1 t}^{1 *} a_{1 t}^{2 *}}{\alpha_{1}}+\frac{a_{2 t}^{1 *} a_{2 t}^{2 *}}{\alpha_{2}}+\frac{c_{1 t}^{1 *} c_{1 t}^{2 *}}{\delta_{1}}+\frac{c_{2 t}^{1 *} c_{2 t}^{2 *}}{\delta_{2}}+\left(a_{1 t}^{1 *} a_{2 t}^{2 *}+a_{2 t}^{1 *} a_{1 t}^{2 *}\right) \rho \\
& =\frac{\left(1-b_{2 t}^{2 *}\right) c_{1 t}^{2 *}-b_{1 t}^{2 *} c_{1 t}^{1 *}}{\delta_{1}}
\end{aligned}
$$

Using these expressions we can compute the correlation coefficient of higher order expectations:

$$
\begin{aligned}
\operatorname{Corr}\left[E_{s}\left(p_{1 t}\right), E_{s}\left(p_{2 t}\right) \mid \theta_{1}, \theta_{2}\right] & =\frac{\operatorname{Cov}\left[\bar{E}_{t}^{s}\left(\theta_{1}\right), \bar{E}_{t}^{s}\left(\theta_{2}\right) \mid \theta_{1}, \theta_{2}\right]}{\sqrt{\operatorname{Var}\left[\bar{E}_{t}^{s}\left(\theta_{1}\right) \mid \theta_{1}, \theta_{2}\right] \cdot \operatorname{Var}\left[\bar{E}_{t}^{s}\left(\theta_{2}\right) \mid \theta_{1}, \theta_{2}\right]}} \\
& =\frac{\frac{\left(1-b_{1 t}^{1 *}\right) c_{2 t}^{1 *}-b_{2 t}^{1 *} c_{2 t}^{2 *}}{\delta_{2}}}{\sqrt{\frac{c_{1 t}^{1 *}\left(1-b_{1 t}^{1 *}\right)-c_{1 t}^{2 *} b_{2 t}^{1 *}}{\delta_{1}} \cdot \frac{c_{2 t}^{2 *}\left(1-b_{2 t}^{2 *}\right)-c_{2 t}^{1 *} b_{1 t}^{2 *}}{\delta_{2}}}}
\end{aligned}
$$

The corresponding correlation of average expectations is given by

$$
\operatorname{Corr}\left[\bar{E}\left(\theta_{1}\right), \bar{E}\left(\theta_{2}\right) \mid \theta_{1}, \theta_{2}\right]=\frac{\frac{c_{12}\left(1-b_{11}\right)-c_{22} b_{12}}{\delta_{2}}}{\sqrt{\frac{c_{11}\left(1-b_{11}\right)-c_{21} b_{12}}{\delta_{1}} \cdot \frac{c_{22}\left(1-b_{22}\right)-c_{12} b_{21}}{\delta_{2}}}}
$$

We need to show that

$$
\operatorname{Corr}\left[\bar{E}_{t}^{s}\left(\theta_{1}\right), \bar{E}_{t}^{s}\left(\theta_{2}\right) \mid \theta_{1}, \theta_{2}\right] \geq \operatorname{Corr}\left[\bar{E}\left(\theta_{1}\right), \bar{E}\left(\theta_{2}\right) \mid \theta_{1}, \theta_{2}\right]
$$

We can distinguish for cases.

1. Both the covariance of HOB and the covariance of average expectations (AE) are positive, 
implying that

$$
\begin{aligned}
c_{2 t}^{1 *}\left(1-b_{1 t}^{1 *}\right)-c_{2 t}^{2 *} b_{2 t}^{1 *}=c_{1 t}^{2 *}\left(1-b_{2 t}^{2 *}\right)-c_{1 t}^{1 *} b_{1 t}^{2 *}>0 \\
c_{12}\left(1-b_{11}\right)-c_{22} b_{12}=c_{21}\left(1-b_{22}\right)-c_{11} b_{21}>0
\end{aligned}
$$

Squaring both sides of the inequality in (51) and making use of the alternative expression for the covariance of HOB in (50) shows that in this case (51) can be written as

$$
\begin{aligned}
& \frac{\left[c_{2 t}^{1 *}\left(1-b_{1 t}^{1 *}\right)-c_{2 t}^{2 *} b_{2 t}^{1 *}\right] \cdot\left[c_{1 t}^{2 *}\left(1-b_{2 t}^{2 *}\right)-c_{1 t}^{1 *} b_{1 t}^{2 *}\right]}{\left[c_{1 t}^{1 *}\left(1-b_{1 t}^{1 *}\right)-c_{1 t}^{2 *} b_{2 t}^{1 *}\right] \cdot\left[c_{2 t}^{2 *}\left(1-b_{2 t}^{2 *}\right)-c_{2 t}^{1 *} b_{1 t}^{2 *}\right]} \\
& \geq \frac{\left[c_{12}\left(1-b_{11}\right)-c_{22} b_{12}\right] \cdot\left[c_{21}\left(1-b_{22}\right)-c_{11} b_{21}\right]}{\left[c_{11}\left(1-b_{11}\right)-c_{21} b_{12}\right] \cdot\left[c_{22}\left(1-b_{22}\right)-c_{12} b_{21}\right]}
\end{aligned}
$$

It turns out that this expression can be split in two separate sufficient conditions,

$$
\begin{aligned}
& \frac{c_{2 t}^{1 *}\left(1-b_{1 t}^{1 *}\right)-c_{2 t}^{2 *} b_{2 t}^{1 *}}{c_{12}\left(1-b_{11}\right)-c_{22} b_{12}} \geq \frac{c_{1 t}^{1 *}\left(1-b_{1 t}^{1 *}\right)-c_{1 t}^{2 *} b_{2 t}^{1 *}}{c_{11}\left(1-b_{11}\right)-c_{21} b_{12}} \\
& \frac{c_{1 t}^{2 *}\left(1-b_{2 t}^{2 *}\right)-c_{1 t}^{1 *} b_{1 t}^{2 *}}{c_{21}\left(1-b_{22}\right)-c_{11} b_{21}} \geq \frac{c_{2 t}^{2 *}\left(1-b_{2 t}^{2 *}\right)-c_{2 t}^{1 *} b_{1 t}^{2 *}}{c_{22}\left(1-b_{22}\right)-c_{12} b_{21}}
\end{aligned}
$$

or equivalently

$$
\begin{gathered}
{\left[c_{2 t}^{1 *}\left(1-b_{1 t}^{1 *}\right)-c_{2 t}^{2 *} b_{2 t}^{1 *}\right] \cdot\left[c_{11}\left(1-b_{11}\right)-c_{21} b_{12}\right]} \\
-\left[c_{1 t}^{1 *}\left(1-b_{1 t}^{1 *}\right)-c_{1 t}^{2 *} b_{2 t}^{1 *}\right] \cdot\left[c_{12}\left(1-b_{11}\right)-c_{22} b_{12}\right] \geq 0 \\
{\left[c_{1 t}^{2 *}\left(1-b_{2 t}^{2 *}\right)-c_{1 t}^{1 *} b_{1 t}^{2 *}\right] \cdot\left[c_{22}\left(1-b_{22}\right)-c_{12} b_{21}\right]} \\
-\left[c_{2 t}^{2 *}\left(1-b_{2 t}^{2 *}\right)-c_{2 t}^{1 *} b_{1 t}^{2 *}\right] \cdot\left[c_{21}\left(1-b_{22}\right)-c_{11} b_{21}\right] \geq 0
\end{gathered}
$$

We show below that both of these conditions hold.

2. Both the covariance of $\mathrm{HOB}$ and the covariance of $\mathrm{AE}$ are negative, implying that

$$
\begin{aligned}
& c_{2 t}^{1 *}\left(1-b_{1 t}^{1 *}\right)-c_{2 t}^{2 *} b_{2 t}^{1 *}=c_{1 t}^{2 *}\left(1-b_{2 t}^{2 *}\right)-c_{1 t}^{1 *} b_{1 t}^{2 *}<0 \\
& c_{12}\left(1-b_{11}\right)-c_{22} b_{12}=c_{21}\left(1-b_{22}\right)-c_{11} b_{21}<0
\end{aligned}
$$

In this case the inequality in (51) can be written equivalently as

$$
\begin{aligned}
& \frac{\left[c_{2 t}^{1 *}\left(1-b_{1 t}^{1 *}\right)-c_{2 t}^{2 *} b_{2 t}^{1 *}\right] \cdot\left[c_{1 t}^{2 *}\left(1-b_{2 t}^{2 *}\right)-c_{1 t}^{1 *} b_{1 t}^{2 *}\right]}{\left[c_{1 t}^{1 *}\left(1-b_{1 t}^{1 *}\right)-c_{1 t}^{2 *} b_{2 t}^{1 *}\right] \cdot\left[c_{2 t}^{2 *}\left(1-b_{2 t}^{2 *}\right)-c_{2 t}^{1 *} b_{1 t}^{2 *}\right]} \\
\leq & \frac{\left[c_{12}\left(1-b_{11}\right)-c_{22} b_{12}\right] \cdot\left[c_{21}\left(1-b_{22}\right)-c_{11} b_{21}\right]}{\left[c_{11}\left(1-b_{11}\right)-c_{21} b_{12}\right] \cdot\left[c_{22}\left(1-b_{22}\right)-c_{12} b_{21}\right]}
\end{aligned}
$$

Rearranging, it turns out that sufficient conditions that ensure that this inequality holds are again given by (52) and (53).

3. The covariance of HOB is positive, but the covariance of AE is negative: in this case our proposition holds anyway.

4. The covariance of $\mathrm{HOB}$ is negative, but the covariance of $\mathrm{AE}$ is positive: this case cannot occur (see proposition 4). 
Thus it is sufficient to prove (52) and (53). Some algebra shows that condition (52) is equivalent to requiring that

$$
C_{0}+C_{1} \cdot\left(\frac{1}{\lambda_{1}}\right)^{s}-C_{2} \cdot\left(\frac{1}{\lambda_{2}}\right)^{s}-C_{11} \cdot\left(\frac{1}{\lambda_{1}}\right)^{2 s}+C_{22} \cdot\left(\frac{1}{\lambda_{2}}\right)^{2 s} \geq 0
$$

where $s=\bar{T}-t$ and the coefficients are defined as

$$
\begin{aligned}
C_{0} & =\frac{b_{12}\left(c_{11} c_{22}-c_{12} c_{21}\right)+\left(c_{11} b_{22}-b_{12} c_{21}\right)\left[c_{12}\left(1-b_{11}\right)-c_{22} b_{12}\right]}{1-\left(b_{11}+b_{22}\right)+\left(b_{11} b_{22}-b_{21} b_{12}\right)}>0 \\
C_{1} & =-2 \frac{1}{\lambda_{1}-\lambda_{2}} \frac{1}{1-\lambda_{1}} K_{1}>0 \\
C_{2} & =-2 \frac{1}{\lambda_{1}-\lambda_{2}} \frac{1}{1-\lambda_{2}} K_{2}>0 \\
C_{11} & =-\frac{1}{\lambda_{1}-\lambda_{2}} \frac{1}{\lambda_{1}\left(1-\lambda_{1}\right)} K_{1}>0 \\
C_{22} & =-\frac{1}{\lambda_{1}-\lambda_{2}} \frac{1}{\lambda_{2}\left(1-\lambda_{2}\right)} K_{2}<0
\end{aligned}
$$

with

$$
\begin{array}{ccc}
K_{1}= & c_{12} \lambda_{2} \cdot\left[c_{11}\left(1-b_{11}\right)-c_{21} b_{12}\right] \\
& -\left[\lambda_{1} \lambda_{2}\left(c_{11} b_{11}+b_{12} c_{21}\right)-\lambda_{1} c_{11}\right] \cdot\left[c_{12}\left(1-b_{11}\right)-c_{22} b_{12}\right] \\
c_{12} \lambda_{1} \cdot\left[c_{11}\left(1-b_{11}\right)-c_{21} b_{12}\right] \\
K_{2}= & -\left[\lambda_{1} \lambda_{2}\left(c_{11} b_{11}+b_{12} c_{21}\right)-\lambda_{2} c_{11}\right] \cdot\left[c_{12}\left(1-b_{11}\right)-c_{22} b_{12}\right]
\end{array}
$$

with $K_{1}, K_{2}>0$. We know that the expression in (54) is equal to zero for $s=0$. Then it is sufficient to show that (54) is increasing in $s$. This proof is very similar to the final steps in the proof of the conditions for excess covariance and therefore omitted. Q.E.D.

\section{Numerical solution of the full model}

The solution method used for numerical simulations of the full model in section five is based on Townsend (1983), adapted to our multi-asset framework. ${ }^{20}$ We start with the educated guess that prices are linear functions of various shocks. Based on the conjectured pricing functions investors' expectations of future prices and fundamentals are computed and equilibrium prices are derived. The final step is then to equate conjectured and equilibrium coefficients.

The contribution of Townsend (1983) was to show that even though higher order beliefs are of infinite order the number of unknown coefficients is finite, as shown below. Therefore this application of the method of undetermined coefficients leads to a fixed-point problem with a finite number of non-linear equations which can be solved by standard methods.

For ease of notation we rewrite the stochastic process for fundamentals as follows:

$$
\theta_{j t}=D_{j}(L) \varepsilon_{j t}
$$

for $j=1,2$, where

$$
D_{j}(L)=d_{1}+d_{2} L+d_{3} L^{2}+\ldots
$$

\footnotetext{
${ }^{20}$ We use the notation of Bacchetta and van Wincoop (2006), extending their analysis to a setting with multiple risky assets.
} 
is an infinite polynomial in the lag operator $L$. Fundamentals follow and AR-1 process so that we have

$$
d_{s}^{j}=\left(\rho_{j}\right)^{s-1} \quad \text { for } s \geq 1
$$

\section{C.1 Conjectured rules for prices}

Conjecture that prices can be expressed in terms of current and past shocks: ${ }^{21}$

$$
\begin{gathered}
p_{j t}=A_{j 1}(L) \varepsilon_{1 t+T}+A_{j 2}(L) \varepsilon_{2 t+T}+C_{j 1}(L) \zeta_{1 t+T} \\
+C_{j 2}(L) \zeta_{2 t+T}+B_{j 1}(L) s_{1 t}+B_{j 2}(L) s_{2 t}
\end{gathered}
$$

where

$$
K_{i j}(L)=k_{1}^{i j}+k_{2}^{i j} L+k_{3}^{i j} L^{2}+\ldots
$$

Note that only fundamental shocks from $t+1$ to $t+T$ are unknown, since fundamentals $\theta_{j t}$ up to $t$ have been observed, so that the shocks can be computed. Since $z_{j t}=\theta_{j t}+\zeta_{j t}$, shocks to the public signal $\zeta_{j t}$ are therefore also known up to $t$ and unknown only for $t+1$ to $t+T$. Furthermore, note that only supply shocks $s_{j t}$ from $t-T+1$ to $t$ are unknown, while shocks from $t-T$ and earlier can be deduced by observing asset prices and fundamentals. With knowledge of shocks to fundamentals in $t$ and earlier, supply shocks from $t-T$ and earlier can be deduced from prices (each period, two supply shocks can be computed from two pricing equations). Therefore we can write the price of asset $j$ in period $t+1$ as follows:

$$
p_{j t+1}=\underbrace{a_{1}^{j 2} \varepsilon_{1 t+T+1}}_{+\underbrace{\boldsymbol{\Theta}_{j}^{\prime} \xi_{t}}+\underbrace{A_{j 1}^{*}(L) \varepsilon_{1 t}+A_{j 2}^{*}(L) \varepsilon_{2 t}+B_{j 1}^{*}(L) s_{1 t-T}+B_{j 2}^{*}(L) s_{2 t-T}}}
$$

where we have defined

$$
\begin{aligned}
& \boldsymbol{\xi}_{t}^{\prime}=\left[\begin{array}{ll}
\boldsymbol{\xi}_{1 t}^{\prime} & \boldsymbol{\xi}_{2 t}^{\prime}
\end{array}\right] \quad \Theta_{j}^{\prime}=\left[\begin{array}{ll}
\Theta_{j 1}^{\prime} & \Theta_{j 2}^{\prime}
\end{array}\right] \\
& \boldsymbol{\xi}_{j t}=\left[\begin{array}{lllllllll}
\varepsilon_{j t+T} & \cdots & \varepsilon_{j t+1} & \zeta_{j t+T} & \cdots & \zeta_{j t+1} & s_{j t} & \cdots & s_{j t-T+1}
\end{array}\right]^{\prime} \\
& \boldsymbol{\Theta}_{i j}^{\prime}=\left[\begin{array}{lllllllll}
a_{2}^{i j} & \cdots & a_{T+1}^{i j} & c_{2}^{i j} & \cdots & c_{T+1}^{i j} & b_{2}^{i j} & \cdots & b_{T+1}^{i j}
\end{array}\right] \\
& K_{i j}^{*}(L)=k_{T+2}^{i j}+k_{T+3}^{i j} L+k_{T+3}^{i j} L^{2}+\ldots
\end{aligned}
$$

Past public signals from $t$ and earlier have no role in forecasting future fundamentals, so that their weight is zero, and no $C^{*}(L)$ terms appear. Note that $\boldsymbol{\xi}_{t}$ contains fundamental, news and supply shocks about which private signals and prices observed in $t$ are informative. Therefore in equation (56) the expectation of shocks in the first term is zero as of period $t$; the shocks in the second term can be forecasted by using the information available in $t$; and the shocks in the final term are known in $t$.

\section{C.2 Conditional moments}

Investors form expectations about unobserved shocks based on their private signals and the information contained in current and past prices. Denote the vector of variables observed by

\footnotetext{
${ }^{21}$ From the law of large numbers private signal noise washes out when integrating across all investors $i$, so that prices do not depend on private signal noise.
} 
investor $i$ in period $t$ by

$$
\begin{aligned}
& \mathbf{Y}_{t}^{i}=\left[\begin{array}{cc}
\mathbf{Y}_{t}^{p \prime} & \mathbf{Y}_{t}^{i x \prime}
\end{array}\right]^{\prime} \\
& \mathbf{Y}_{t}^{p}=\left[\begin{array}{llllll}
p_{1 t}^{*} & \cdots & p_{1 t-T+1}^{*} & p_{2 t}^{*} & \cdots & p_{2 t-T+1}^{*}
\end{array}\right]^{\prime}
\end{aligned}
$$

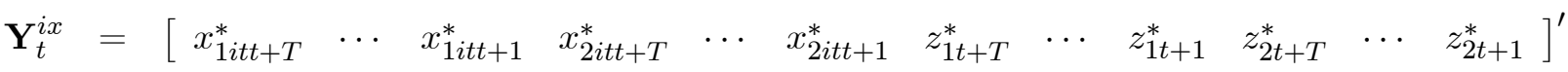

where variables that have a star superscript denote observables. For example, for private signals, note that

$$
\begin{aligned}
x_{1 i t s} & =\theta_{1 s}+\eta_{1 i t s} \\
& =\underbrace{d_{1} \varepsilon_{1 s}+. .+d_{s-t} \varepsilon_{1 t+1}}+\underbrace{d_{s-t-1} \varepsilon_{1 t}+d_{s-t-2} \varepsilon_{1 t-1}+\ldots}+\eta_{1 i t s}
\end{aligned}
$$

where the first term is unobserved at $t$, while the second term can be computed at $t$ from the fundamentals which have been observed. Then the observable part of the private signal is given by

$$
\begin{aligned}
x_{1 i t s}^{*} & =x_{1 i t s}-d_{s-t-1} \varepsilon_{1 t}-d_{s-t-2} \varepsilon_{1 t-1}-\ldots \\
& =d_{1} \varepsilon_{1 s}+\ldots+d_{s-t} \varepsilon_{1 t+1}+\eta_{1 i t s}
\end{aligned}
$$

We can write

$$
\mathbf{Y}_{t}^{i}=\mathbf{H}^{\prime} \boldsymbol{\xi}_{t}+\mathbf{w}_{t}^{i}
$$

where $\mathbf{H}^{\prime}$ is defined as follows:

$$
\mathbf{H}^{\prime}=\left[\begin{array}{cccccc}
\mathbf{A}_{11} & \mathbf{C}_{11} & \mathbf{B}_{11} & \mathbf{A}_{12} & \mathbf{C}_{12} & \mathbf{B}_{12} \\
\mathbf{A}_{21} & \mathbf{C}_{21} & \mathbf{B}_{21} & \mathbf{A}_{22} & \mathbf{C}_{22} & \mathbf{B}_{22} \\
\mathbf{D}_{1} & \mathbf{0} & \mathbf{0} & \mathbf{0} & \mathbf{0} & \mathbf{0} \\
\mathbf{0} & \mathbf{0} & \mathbf{0} & \mathbf{D}_{2} & \mathbf{0} & \mathbf{0} \\
\mathbf{D}_{1} & \mathbf{I}_{T} & \mathbf{0} & \mathbf{0} & \mathbf{0} & \mathbf{0} \\
\mathbf{0} & \mathbf{0} & \mathbf{0} & \mathbf{D}_{2} & \mathbf{I}_{T} & \mathbf{0}
\end{array}\right]
$$

with

$$
\mathbf{K}_{i j}=\left[\begin{array}{ccc}
k_{1}^{i j} & \cdots & k_{T}^{i j} \\
& \ddots & \vdots \\
& & k_{1}^{i j}
\end{array}\right]
$$

where empty entries are equal to zero, and

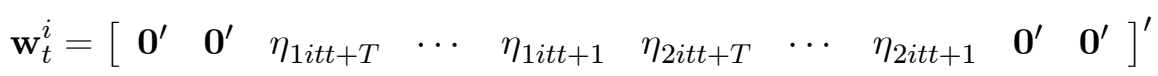

A typical investor $i$ in period $t$ observes the vector $\mathbf{Y}_{t}^{i}$ and can form expectations about $\boldsymbol{\xi}_{t}$ conditional on $\mathbf{Y}_{t}^{i}$, using the projection theorem. Note that the unconditional expectation of both $\boldsymbol{\xi}_{t}$ and $\mathbf{w}_{t}^{i}$ is zero. For the unconditional variances we have

$$
\operatorname{Var}\left(\mathbf{w}_{t}^{i}\right) \equiv \mathbf{R}=\left[\begin{array}{cccc}
\multicolumn{4}{c}{\mathbf{0}_{2 T \times 6 T}} \\
\hline \mathbf{0}_{T \times 2 T} & \sigma_{x 1}^{2} \mathbf{I}_{T} & \mathbf{0}_{T \times T} & \mathbf{0}_{T \times 2 T} \\
\mathbf{0}_{T \times 2 T} & \mathbf{0}_{T \times T} & \sigma_{x 2}^{2} \mathbf{I}_{T} & \mathbf{0}_{T \times 2 T} \\
\hline \multicolumn{4}{c}{\mathbf{0}_{2 T \times 6 T}}
\end{array}\right]
$$


and

$$
\operatorname{Var}\left(\boldsymbol{\xi}_{t}\right) \equiv \widetilde{\mathbf{P}}=\left[\begin{array}{cc}
\widetilde{\mathbf{P}}_{1} & \widetilde{\mathbf{P}}_{12} \\
\widetilde{\mathbf{P}}_{12}^{\prime} & \widetilde{\mathbf{P}}_{2}
\end{array}\right]
$$

with

$$
\begin{aligned}
\operatorname{Var}_{t}\left(\boldsymbol{\xi}_{j t}\right) & \equiv \widetilde{\mathbf{P}}_{j}=\left[\begin{array}{ccc}
\sigma_{j}^{2} \mathbf{I}_{T} & \mathbf{0} & \mathbf{0} \\
\mathbf{0} & \sigma_{z j}^{2} \mathbf{I}_{T} & \mathbf{0} \\
\mathbf{0} & \mathbf{0} & \sigma_{s j}^{2} \mathbf{I}_{T}
\end{array}\right] \\
\operatorname{Cov}_{t}\left(\boldsymbol{\xi}_{1 t}, \boldsymbol{\xi}_{2 t}\right) & \equiv \widetilde{\mathbf{P}}_{12}=\left[\begin{array}{ccc}
\rho_{\theta} \mathbf{I}_{T} & \mathbf{0} & \mathbf{0} \\
\mathbf{0} & \mathbf{0} & \mathbf{0} \\
\mathbf{0} & \mathbf{0} & \rho_{s} \mathbf{I}_{T}
\end{array}\right]
\end{aligned}
$$

where all empty entries are zero. Then the projection theorem gives

$$
\begin{aligned}
E\left(\boldsymbol{\xi}_{t} \mid \mathbf{Y}_{t}^{i}\right) & =\mathbf{M} \mathbf{Y}_{t}^{i} \\
\operatorname{Var}\left(\boldsymbol{\xi}_{t} \mid \mathbf{Y}_{t}^{i}\right) & \equiv \mathbf{P}=\widetilde{\mathbf{P}}-\mathbf{M H}^{\prime} \widetilde{\mathbf{P}}
\end{aligned}
$$

where

$$
\mathbf{M}=\widetilde{\mathbf{P}} \mathbf{H}\left(\mathbf{H}^{\prime} \widetilde{\mathbf{P}} \mathbf{H}+\mathbf{R}\right)^{-1}
$$

From the conjectured pricing equation (55) expectations of next period's prices are given by

$$
\begin{aligned}
& E_{i t}\left(p_{j t+1}\right)=\quad \boldsymbol{\Theta}_{j}^{\prime} E_{i t}\left(\boldsymbol{\xi}_{t}\right)+A_{j 1}^{*}(L) \varepsilon_{1 t} \\
& +A_{j 2}^{*}(L) \varepsilon_{2 t}+B_{j 1}^{*}(L) s_{1 t-T}+B_{j 2}^{*}(L) s_{2 t-T}
\end{aligned}
$$

Substituting and averaging across investors, the law of large numbers gives

$$
\bar{E}_{t}\left(p_{j t+1}\right)=\mathbf{\Theta}_{j}^{\prime} \mathbf{M H}^{\prime} \boldsymbol{\xi}_{t}+A_{j 1}^{*}(L) \varepsilon_{1 t}+A_{j 2}^{*}(L) \varepsilon_{2 t}+B_{j 1}^{*}(L) s_{1 t-T}+B_{j 2}^{*}(L) s_{2 t-T}
$$

For the (co-)variances we have

$$
\begin{array}{cc}
\operatorname{Var}_{t}\left(p_{j 1 t+1}\right)= & \left(a_{1}^{j 1}\right)^{2} \sigma_{1}^{2}+\left(a_{1}^{j 2}\right)^{2} \sigma_{2}^{2}+2 a_{1}^{j 1} a_{1}^{j 2} \rho_{\theta} \\
& +\left(c_{1}^{j 1}\right)^{2} \sigma_{z 1}^{2}+\left(c_{1}^{j 2}\right)^{2} \sigma_{z 2}^{2}+\mathbf{\Theta}_{j}^{\prime} \mathbf{P} \Theta_{j} \\
& +\left(b_{1}^{j 1}\right)^{2} \sigma_{s 1}^{2}+\left(b_{1}^{j 2}\right)^{2} \sigma_{s 2}^{2}+2 b_{1}^{j 1} b_{1}^{j 2} \rho_{s} \\
\operatorname{Cov}_{t}\left(p_{1 t+1}, p_{2 t+1}\right)=\quad & a_{1}^{11} a_{1}^{21} \sigma_{1}^{2}+a_{1}^{12} a_{1}^{22} \sigma_{2}^{2}+\left(a_{1}^{11} a_{1}^{22}+a_{1}^{12} a_{1}^{21}\right) \rho_{\theta} \\
& +c_{1}^{11} c_{1}^{21} \sigma_{z 1}^{2}+c_{1}^{12} c_{1}^{22} \sigma_{z 2}^{2}+\mathbf{\Theta}_{1}^{\prime} \mathbf{P} \Theta_{2} \\
& +b_{1}^{11} b_{1}^{21} \sigma_{s 1}^{2}+b_{1}^{12} b_{1}^{22} \sigma_{s 2}^{2}+\left(b_{1}^{11} b_{1}^{22}+b_{1}^{12} b_{1}^{21}\right) \rho_{s}
\end{array}
$$

Next, consider expectations of future fundamentals. What matters for prices in $t$ are the expectations of $\theta_{j t+1}$,

$$
E_{i t}\left(\theta_{1 t+1}\right)=d_{1}^{j} E_{i t}\left(\varepsilon_{j t+1} \mid \mathbf{Y}_{t}^{i}\right)+d_{2}^{j} \varepsilon_{j t}+d_{3}^{j} \varepsilon_{j t-1}+\ldots
$$

Note that $\varepsilon_{1 t+1}$ is the $T$ th element in the vector $\boldsymbol{\xi}_{t}$, and $\varepsilon_{2 t+1}$ the $4 T$ th element in the vector $\boldsymbol{\xi}_{t}$. Letting $\mathbf{M}^{T}$ and $\mathbf{M}^{4 T}$ denote the $T$ th and $4 T$ th row of $\mathbf{M}$, respectively, substituting and 
averaging across investors then yields

$$
\begin{aligned}
& \bar{E}_{t}\left(\theta_{1 t+1}\right)=d_{1}^{1} \mathbf{M}^{T} \mathbf{H}^{\prime} \boldsymbol{\xi}_{t}+d_{2}^{1} \varepsilon_{1 t}+d_{3}^{1} \varepsilon_{1 t-1}+\ldots \\
& \bar{E}_{t}\left(\theta_{2 t+1}\right)=d_{1}^{2} \mathbf{M}^{4 T} \mathbf{H}^{\prime} \boldsymbol{\xi}_{t}+d_{2}^{2} \varepsilon_{2 t}+d_{3}^{2} \varepsilon_{2 t-1}+\ldots
\end{aligned}
$$

Furthermore, we have

$$
\begin{aligned}
\operatorname{Var}_{t}\left(\theta_{1 t+1}\right) & =\left(d_{1}^{1}\right)^{2} \operatorname{Var}_{t}\left(\varepsilon_{1 t+1}\right)=\left(d_{1}^{1}\right)^{2} \mathbf{P}^{T, T} \\
\operatorname{Var}_{t}\left(\theta_{2 t+1}\right) & =\left(d_{1}^{2}\right)^{2} \operatorname{Var}_{t}\left(\varepsilon_{2 t+1}\right)=\left(d_{1}^{2}\right)^{2} \mathbf{P}^{4 T, 4 T} \\
\operatorname{Cov}_{t}\left(\theta_{1 t+1}, \theta_{2 t+1}\right) & =d_{1}^{1} d_{1}^{2} \operatorname{Cov}_{t}\left(\varepsilon_{1 t+1}, \varepsilon_{2 t+1}\right)=d_{1}^{1} d_{1}^{2} \mathbf{P}^{T, 4 T}
\end{aligned}
$$

where $\mathbf{P}^{T}$ denotes the $(T, T)$ th element in $\mathbf{P}^{T}$. Note that the covariances of future prices and fundamentals are also non-zero. We have

$$
\begin{aligned}
& \operatorname{Cov}_{t}\left(\theta_{1 t+1}, p_{1 t+1}\right)=d_{1}^{1} a_{T+1}^{11} \mathbf{P}^{T}+d_{1}^{1} a_{T+1}^{12} \mathbf{P}^{T, 4 T} \\
& \operatorname{Cov}_{t}\left(\theta_{1 t+1}, p_{2 t+1}\right)=d_{1}^{1} a_{T+1}^{21} \mathbf{P}^{T}+d_{1}^{1} a_{T+1}^{22} \mathbf{P}^{T, 4 T} \\
& \operatorname{Cov}_{t}\left(\theta_{2 t+1}, p_{1 t+1}\right)=d_{1}^{2} a_{T+1}^{11} \mathbf{P}^{T, 4 T}+d_{1}^{2} a_{T+1}^{12} \mathbf{P}^{4 T} \\
& \operatorname{Cov}_{t}\left(\theta_{2 t+1}, p_{2 t+1}\right)=d_{1}^{2} a_{T+1}^{21} \mathbf{P}^{T, 4 T}+d_{1}^{2} a_{T+1}^{22} \mathbf{P}^{4 T}
\end{aligned}
$$

\section{C.3 Solution}

To solve the model we can then match coefficients from conjectured and equilibrium prices. For example the conjectured price of asset 1 is given by (55) while the equilibrium price is

$$
p_{1 t}=\frac{1}{R} \cdot\left\{\begin{array}{c}
\left(\mathbf{\Theta}_{1}^{\prime} \mathbf{M}_{1}+d_{1}^{1} \mathbf{M}^{T}\right) \cdot \mathbf{H}^{\prime} \boldsymbol{\xi}_{t} \\
+\left(a_{T+2}^{11}+d_{2}^{1}\right) \varepsilon_{1 t}+\left(a_{T+3}^{11}+d_{3}^{1}\right) \varepsilon_{1 t-1}+\ldots+a_{T+2}^{12} \varepsilon_{2 t}+a_{T+3}^{12} \varepsilon_{2 t-1} \\
+b_{T+2}^{11} s_{1 t-T}+b_{T+3}^{11} s_{1 t-T-1}+\ldots+b_{T+2}^{12} s_{2 t-T}+b_{T+3}^{12} s_{2 t-T-1} \\
-\gamma \operatorname{Var}_{t}\left(p_{1 t+1}+\theta_{1 t+1}\right) \cdot\left[s_{1 t}+\phi_{1} s_{1 t-1}+\left(\phi_{1}\right)^{2} s_{1 t-2}+\ldots\right] \\
-\gamma \operatorname{Cov}_{t}\left(p_{1 t+1}+\theta_{1 t+1}, p_{2 t+1}+\theta_{2 t+1}\right) \cdot\left[s_{2 t}+\phi_{2} s_{2 t-1}+\left(\phi_{2}\right)^{2} s_{1 t-2}+\ldots\right]
\end{array}\right\}
$$

In principle we would have to match an infinite number of coefficients. However, by equating conjectured and equilibrium coefficients for shocks from periods $t-T$ and earlier it is observed that only a finite number of coefficients are unknown. Matching supply shock coefficients for shocks from $t-T$, solving forward and assuming stable coefficients yields

$$
\begin{aligned}
b_{T+1}^{11} & =-\frac{\gamma \operatorname{Var}_{t}\left(p_{1 t+1}+\theta_{1 t+1}\right) \cdot\left(\phi_{1}\right)^{T}}{R-\phi_{1}} \\
b_{T+1}^{12} & =-\frac{\gamma \operatorname{Cov}_{t}\left(p_{1 t+1}+\theta_{1 t+1}, p_{2 t+1}+\theta_{2 t+1}\right) \cdot\left(\phi_{2}\right)^{T}}{R-\phi_{2}} \\
b_{T+1}^{21} & =-\frac{\gamma \operatorname{Cov}_{t}\left(p_{1 t+1}+\theta_{1 t+1}, p_{2 t+1}+\theta_{2 t+1}\right) \cdot\left(\phi_{1}\right)^{T}}{R-\phi_{1}} \\
b_{T+1}^{22} & =-\frac{\gamma \operatorname{Var}_{t}\left(p_{2 t+1}+\theta_{2 t+1}\right) \cdot\left(\phi_{2}\right)^{T}}{R-\phi_{2}}
\end{aligned}
$$

and

$$
b_{T+s}^{i j}=\left(\phi_{j}\right)^{s-1} b_{T+1}^{i j}
$$


for $s \geq 2$. Note that (58) to (61) depend on yet undetermined coefficients through the conditional (co-) variances, while (62) can be computed directly once we have solved for (58) to (61). Next we turn to the coefficients of fundamental noise for shocks from $t$ and earlier (shocks that are known in $t$ ). Equating coefficients, solving forward and assuming stable coefficients yields

$$
\begin{array}{llll}
a_{T+1}^{11} & =\frac{\rho_{1}}{R-\rho_{1}} \quad \text { and } & a_{T+s}^{11}=\left(\rho_{1}\right)^{s-1} a_{T+1}^{11} & \text { for } s \geq 2 \\
a_{T+s}^{12}=0 \quad \text { for } s \geq 1 & & \\
a_{T+1}^{22}=\frac{\rho_{2}}{R-\rho_{2}} \quad \text { and } & a_{T+s}^{22}=\left(\rho_{2}\right)^{s-1} a_{T+1}^{22} & \text { for } s \geq 2 \\
a_{T+s}^{21}=0 \quad \text { for } s \geq 1 & &
\end{array}
$$

These coefficients can also computed directly.

It follows that coefficients $a_{T+s}^{i j}$ for $s \geq 1$ and $b_{T+s}^{i j}$ for $s \geq 2$ are known, while coefficients of public signal noise $c_{T+s}^{i j}$ for $s \geq 1$ are equal to zero. For the remaining finite number of unknown coefficients we then have to solve a fixed-point problem with $12 T+4$ equations. The first $4 T$ equations equate the coefficients $a_{1}^{i j}$ to $a_{T}^{i j}$, the next $4 T$ equations equate the coefficients $c_{1}^{i j}$ to $c_{T}^{i j}$, another $4 T$ equations equate the coefficients $b_{1}^{i j}$ to $b_{T}^{i j}$, and the last four equations are given by (58) to (61). We solve this fixed-point problem using the built-in MATLAB routine fsolve. 